\title{
THE TREATMENT OF DISPLACED FRACTURES AT THE ANKLE BY RIGID INTERNAL FIXATION AND EARLY JOINT MOVEMENT
}

\author{
H. Nevile Burwell and Arnold D. Charnley, Dewsbury, England \\ From the Orthopaedic and Accident Service of the Dewsbury Group of Hospitals
}

The purpose of this study is to show that accurate reduction and firm fixation of fractures involving the ankle followed by joint exercises within a few days of operation leads to rapid return of function with consistently good results.

Method of treatment-The injuries in this series were treated by open reduction and internal fixation of one or more fractures in order to stabilise the ankle sufficiently to permit active exercise of the joints in bed without delay. When full movements of the ankle and foot had been restored and the swelling had subsided, a below-knee plaster was applied, in which full weight was taken and near normal activity encouraged. The plaster was retained for a relatively short period; after its removal movements were rapidly regained, further remedial treatment being usually unnecessary.

\section{CLASSIFICATION}

Some preliminary discussion is necessary because the ankle injuries reported in this paper are classified in a manner which is not yet in general use.

The description of ankle fractures was first put on a sound basis by Ashurst and Bromer (1922), whose work, with modification (Bonnin 1950, Watson-Jones 1955), has been generally accepted. Further development has been made possible by the experimental and clinical investigations of Lauge-Hansen $(1948,1950,1952,1954)$ who placed the individual components of an ankle injury in their correct sequence in time so that, when the end point is represented by a fracture, the presence of intermediary ligament injuries may be inferred. This classification, described by its author as " genetic," is therefore a valuable aid to understanding the mechanism of ankle fractures and provides a key to their reduction. Although in general use by Scandinavian writers (Vasli 1957, Klossner 1962, Cedell and Wiberg 1962), it does not appear to have been used more widely although Jergesen (1959), Quigley (1959) and Rose (1962) referred to it. It is used in the description of the injuries presented in this paper.

Lauge-Hansen divided ankle fractures into four main types referred to as supinationeversion (SE), pronation-eversion (PE), supination-adduction (SA) and pronation-abduction (PA). In each type the first word of the designation refers to the posture of the foot at the moment of injury, while the second word indicates the direction of movement of the talus in relation to the leg in accordance with the usual convention. It should be noted that LaugeHansen used the term eversion for lateral rotation, but we prefer to use the latter in order to avoid ambiguity, because eversion is one of the normal movements of the foot. A fifth type designated pronation-dorsiflexion (PD) includes less common injuries, namely anterior marginal fractures and certain fractures of the lower tibial shaft which also involve the ankle. The sequence of events for each of the four main types of fracture together with outline radiographs showing the characteristic injuries is shown in Figure 1 and will be described below.

Eversion (lateral rotation) fractures. Supination-lateral rotation (SL)-Produced by lateral rotation of the supinated foot; the talus rotates against the lateral malleolus, rupturing the anterior tibio-fibular ligament (stage 1) and then causing a spiral or oblique fracture of the lateral malleolus (stage 2); further lateral rotation of the talus will rupture the posterior tibio-fibular ligament or fracture the posterior tibial margin (stage 3). The medial ligament, initially relaxed because of supination, now comes under tension and may rupture or produce fracture of the medial malleolus (stage 4) (Figs. 2 to 5). 
Pronation-lateral rotation ( $P L$ )-Produced by lateral rotation of the pronated foot; the medial ligament already in tension either ruptures or pulls away the medial malleolus (stage 1); the rotating talus then bears upon the anterior border of the lateral malleolus, rupturing the anterior tibio-fibular ligament and the interosseous ligament (stage 2): the next stage is a short spiral fracture of the fibula typically at a level three inches above the ankle joint but not infrequently at a higher level (stage 3); finally, continued application of the lateral rotation force will produce a fracture of the posterior tibial margin or a rupture of the posterior tibio-fibular ligament (stage 4) (Figs. 6 to 9).

Adduction fracture. Supination-adduction $(S A)$-The designation may without loss of clarity be shortened to "supination" (S). A traction fracture of the lateral malleolus at or below the level of the ankle joint, or rupture of the talo-fibular ligaments occurs in stage 1, and a near vertical fracture of the medial malleolus in stage 2 (Figs. 10 and 11).
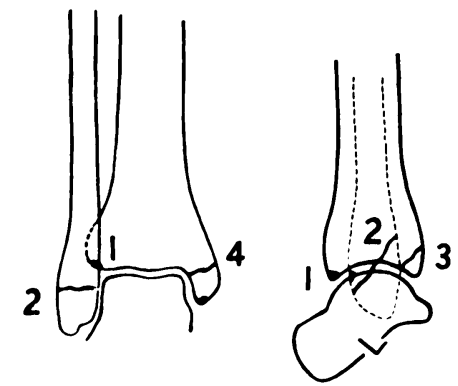

SUPNATION LATERAL ROTATION
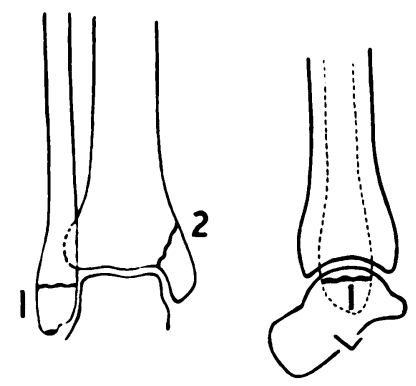

SUPINATION
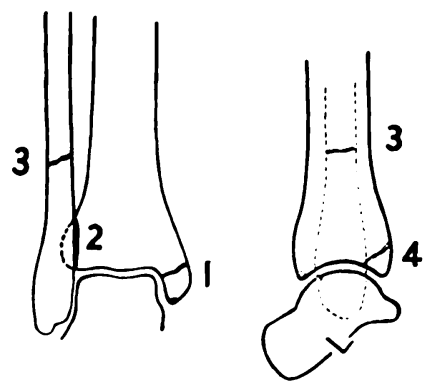

PRONATION LATERAL ROTATION
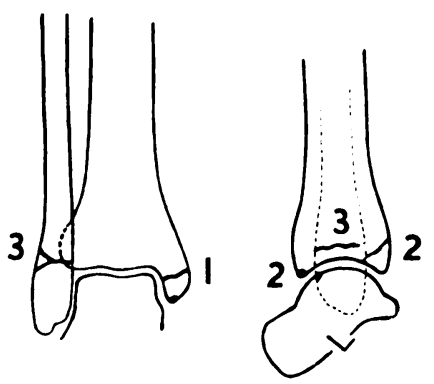

PRONATION

FiG. 1

The four common types of fracture in the Lauge-Hansen classification.

Abduction fracture. Pronation-abduction $(P A)$-This may similarly be abbreviated to "pronation" (P). There is fracture of the medial malleolus or rupture of the medial ligament (stage 1); next, both anterior and posterior tibio-fibular ligaments rupture (stage 2); finally, a bending fracture of the fibula occurs, generally just above the level of the ankle joint, often associated with displacement of a triangular fragment from the lateral surface of the fibula (stage 3) (Figs. 12 and 13).

Compression fracture. Pronation-dorsiflexion $(P D)$-These fractures are usually caused by a fall from a height, the foot moving into dorsiflexion so that the wider anterior part of the talus engages the ankle mortise. The medial malleolus is split off (stage 1); next, pressure from the upper surface of the talus causes fracture of the anterior part of the tibial articular surface (stage 2), and then fracture of the fibula usually in its lowest third (stage 3). Finally, the tibia may break transversely at the level of the proximal margin of the articular fracture described above. 
This classification has the great advantage that with the exception of the stage 1 fractures of the P and PL groups, the different types of injury may be readily distinguished by the nature of the fibular fracture which is characteristic for each type. The presence of ligamentous injuries may in all cases be inferred by a consideration of the nature of the fractures; moreover, in many cases close inspection of the radiographs will reveal the presence of small avulsion fractures at the site of ligamentous attachment. Not infrequently these small

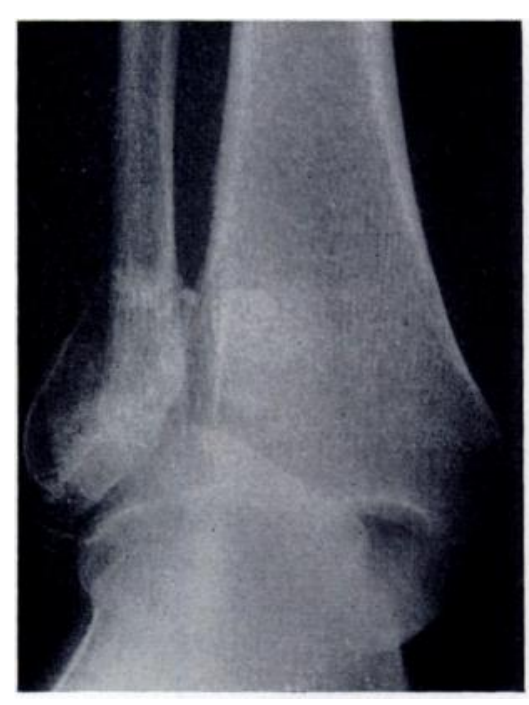

Fig. 2

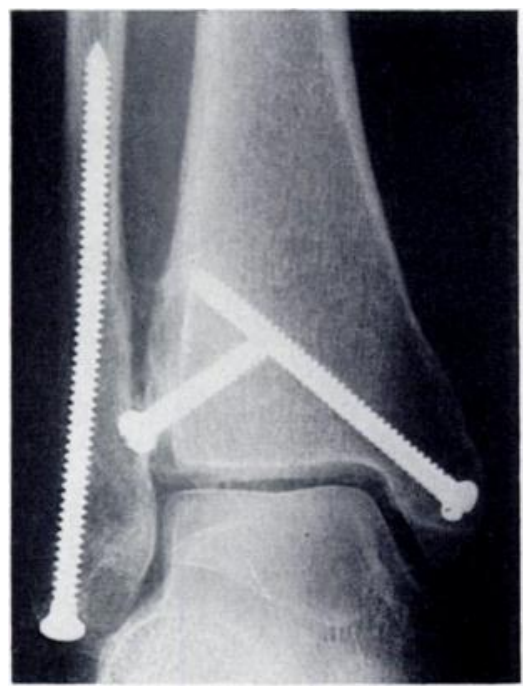

Fig. 4

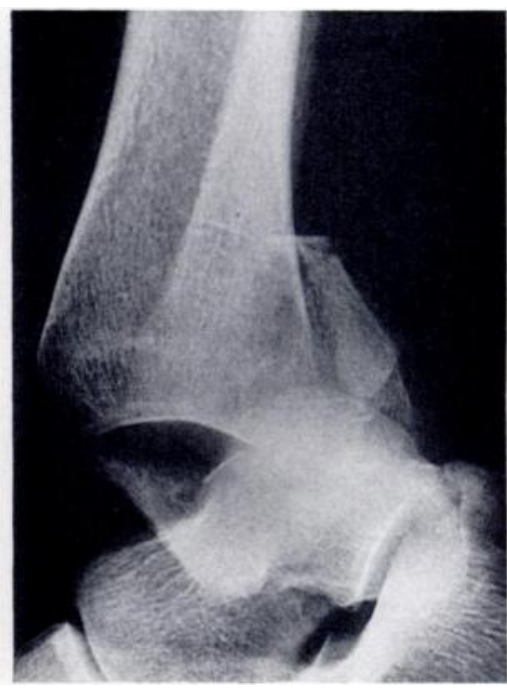

Fig. 3

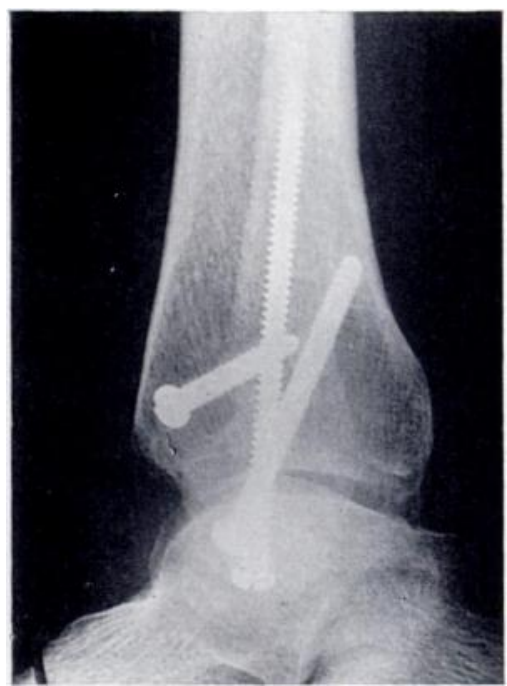

Fig. 5

Radiographs showing SL4 fracture. Figures 2 and 3-Before reduction. Figures 4 and 5-After reduction; note the fixation of the anterior tibial tubercle.

fragments of bone are best seen in films exposed some little time after the injury (Figs. 26 and 28); Lauge-Hansen found such fractures in 55 per cent of his cases and Magnusson (1944) reported an incidence of 74 per cent.

Lauge-Hansen felt that the practical value of his classification was in the closed reduction of ankle displacement. It is also of importance when internal fixation of the fractures is employed because it provides information concerning the associated ligament injuries, and so 
indicates the extent of fixation of the fractures which is likely to be necessary in order to make the ankle stable.

The classification in practice-In the present series the injuries to 126 ankles (out of 135) fell readily into one or other of the four main groups. Of the remaining nine (shown in the tables and histograms as "other "), three were of the PD type, and one resembled a PL4 fracture, being excluded from that group only because the fibular fracture was double. Five of the injuries ( 3.7 per cent of the total number) had been caused by falls from a height or by direct

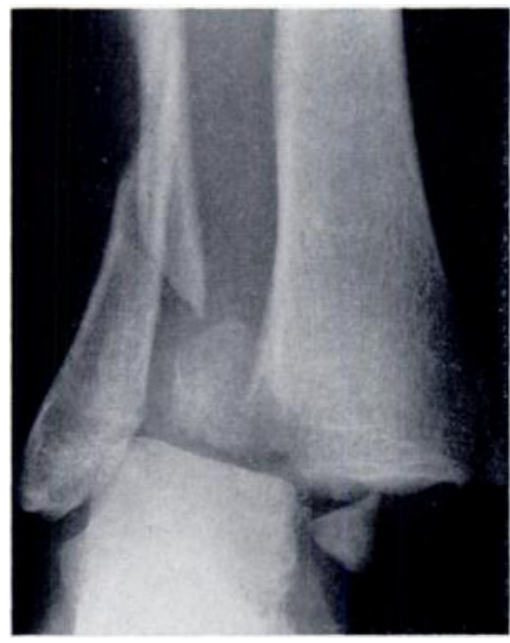

FIG. 6

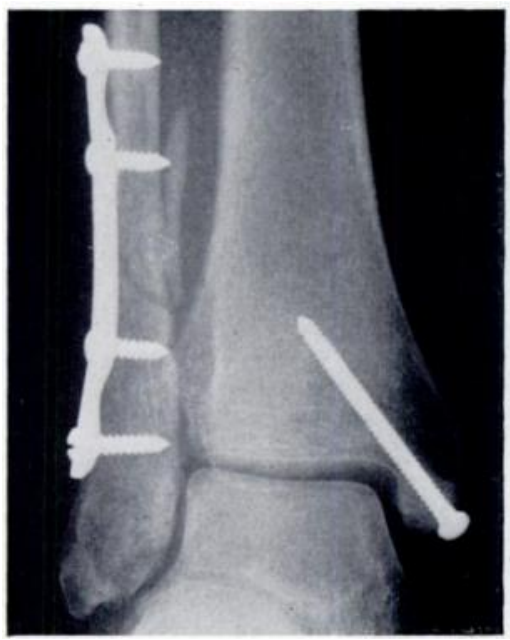

Fig. 8

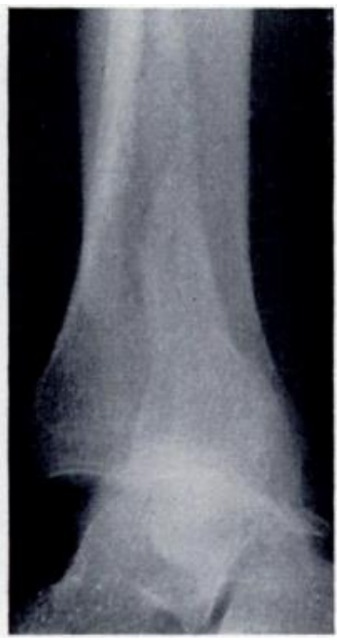

FIG. 7

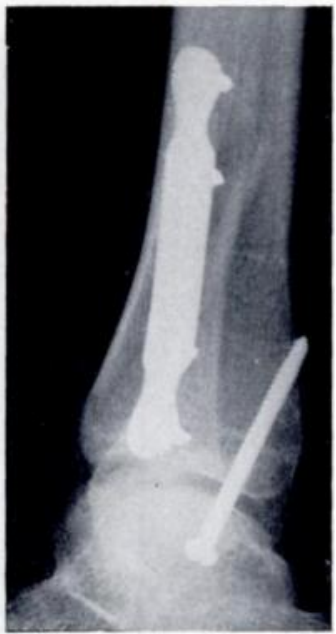

FIG. 9

Radiographs showing PL4 fracture. Figures 6 and 7-Before reduction. Figures 8 and $9-$ After reduction.

violence in traffic accidents and could not be fitted into the general classification. Previous authors report a similar incidence of unclassified material, for instance 1.6 per cent (Vasli 1957) and 3 per cent (Klossner 1962).

With regard to supination fractures it is felt that Lauge-Hansen's views may be too rigid in that he maintained that the first stage injury is fracture of the lateral malleolus (or rupture of the talo-fibular ligaments) with fracture of the medial malleolus occurring only in the second stage. Three patients in this series had sustained a medial malleolar fracture which was 
clearly of supination or adduction type, the fracture line being vertical, but without either fibular fracture or any clinical sign of ligamentous injury on the lateral side of the joint. It seems likely therefore that either the medial or the lateral malleolus may fracture in stage 1, stage 2 being represented by a combination of these injuries, as noted by Bonnin (1950) and by Mitchell and Fleming (1959). In addition, there were two patients whose injuries had clearly been of the supination type, but who in addition to fractures of the medial and lateral malleoli

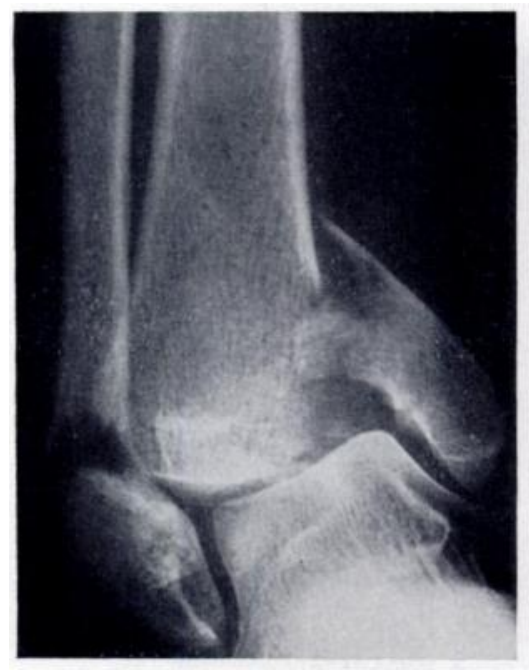

FIG. 10

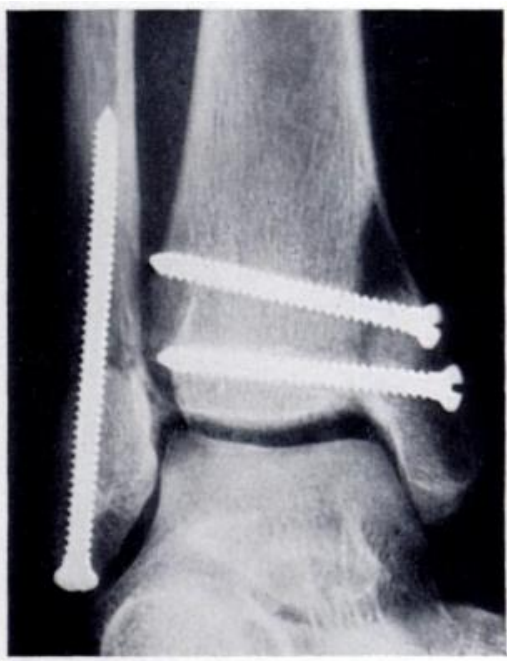

Fic. 11

Radiographs showing S2 fracture before and after reduction.

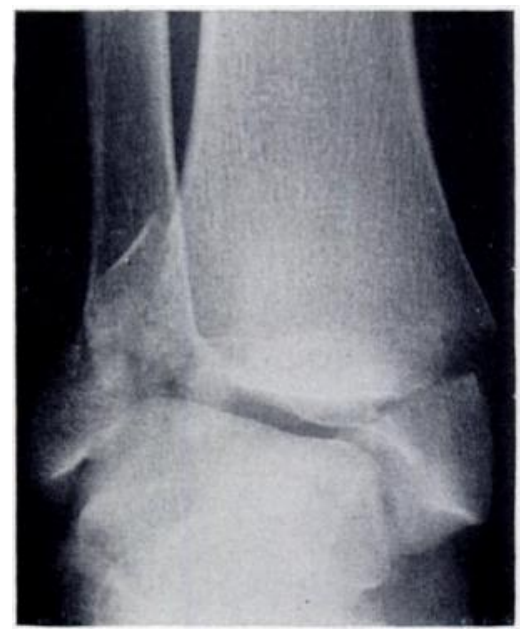

FIG. 12

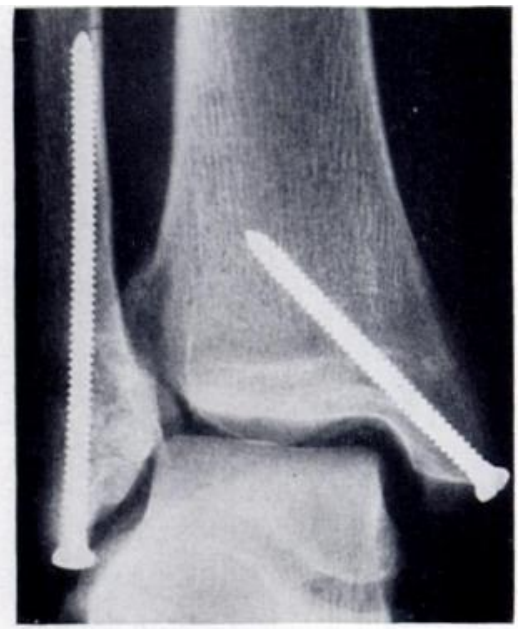

FIG. 13

Radiographs showing P3 fracture before and after reduction.

had fragments broken off the posterior margin of the tibia. Klossner (1962) reported three such instances in his series.

Isolated fractures of the posterior tibial margin, although not described by Lauge-Hansen, were noted by Magnusson ( 3.4 per cent of his cases), by Kleiger (1954) and by Bonnin (1950) who considered that they might be caused by kicking against a solid object.

Despite the need for slight modification as indicated, it seems clear that Lauge-Hansen's classification is the most satisfactory of those available. 


\section{MATERIAL}

This study is based on a consecutive series of 135 patients who had sustained displaced fractures at the ankle; all of them were treated by operation at one hospital during the years 1955-62. The unimalleolar fractures which are included in the series have been either fractures of the medial malleolus or fractures involving the anterior part of the tibial articular surface. During the same period a total of 721 patients with ankle fractures of a lesser degree of severity, mostly of the lateral malleolus, were treated without operation. The present series thus

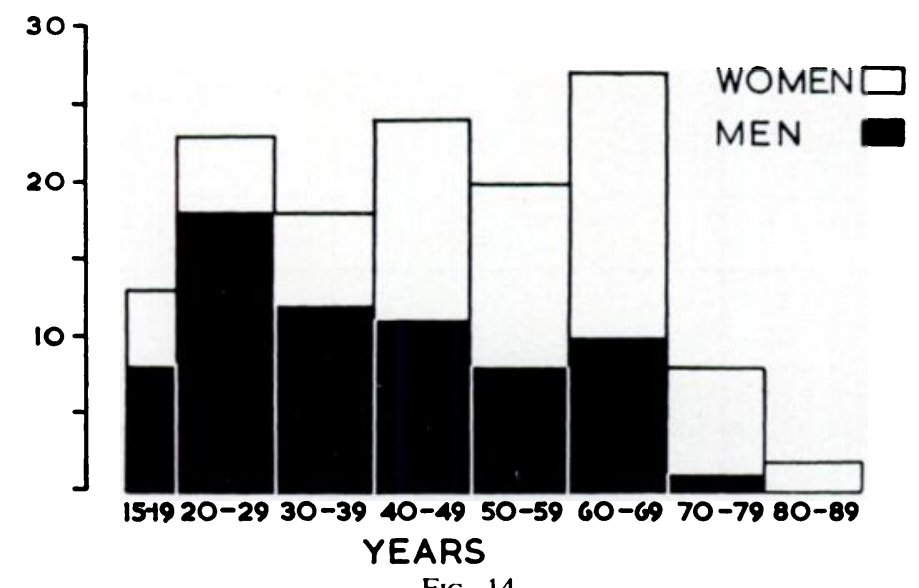

FiG. 14

Distribution of patients according to age and sex.

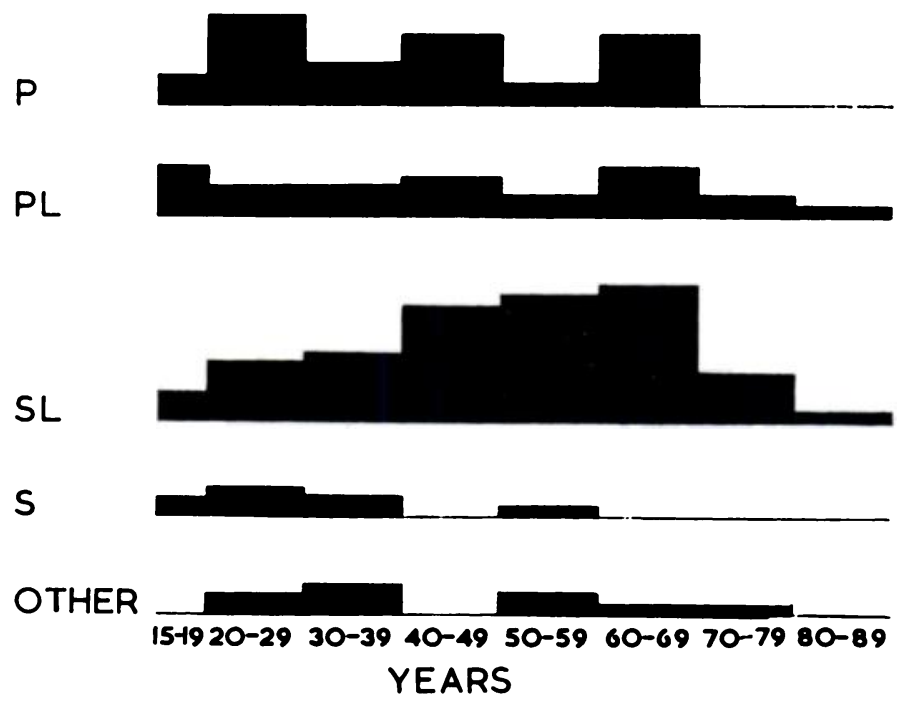

Fig. 15

Distribution of fracture types according to age of patient.

forms 15.8 per cent of the total patients available. Two patients died before adequate assessment of ankle function was possible and one patient, whose fracture was complicated by severe vascular injury, required amputation; these patients appear in the classification but have been excluded from the results. All patients have been followed up clinically and radiographically for an average period of thirty-four months, the limits being twelve months and eight years. Age and sex-The analysis of patients according to age and sex is shown in Figures 14 and 15. Occupation-The occupation of the patients is shown in Table I.

VOL. 47 B, NO. 4, NOVEMBER 1965 
TABLE I

Types of Fracture in Relation to Occupation

\begin{tabular}{|l|c|c|c|c|c|c|c|}
\hline \multirow{2}{*}{ Occupation } & \multicolumn{5}{|c|}{ Type of fracture } & Total & Percentage \\
\cline { 2 - 7 } & P & PL & SL & S & Other & & \\
\hline Manual & 19 & 16 & 25 & 6 & 9 & 75 & 56 \\
\hline Housewife & 5 & 6 & 26 & - & - & 37 & 28 \\
\hline Clerical & 4 & - & 5 & - & - & 9 & 6.7 \\
\hline Pensioner & 2 & 2 & 5 & - & - & 9 & 6.7 \\
\hline Student & 2 & 1 & - & 2 & - & 5 & 3.5 \\
\hline \multicolumn{1}{|c|}{ Total } & 32 & 25 & 61 & 8 & 9 & 135 & 100 \\
\hline
\end{tabular}

TABLE II

Distribution of InJURies According to the Nature of the Accident

\begin{tabular}{|c|c|c|c|c|c|c|c|}
\hline \multirow{2}{*}{ Nature of accident } & \multicolumn{5}{|c|}{ Type of fracture } & \multirow{2}{*}{ Total } & \multirow{2}{*}{ Percentage } \\
\hline & $\mathbf{P}$ & PL & $\mathbf{S L}$ & $\mathbf{S}$ & Other & & \\
\hline Slipping or stumbling. & 8 & 11 & 42 & 1 & - & 62 & 46 \\
\hline Blow outer side leg & 6 & 2 & 一 & - & - & 8 & 6 \\
\hline Fall from stool or steps & 3 & 4 & 13 & 一 & 1 & 21 & 15 \\
\hline Fall from a height & 5 & 1 & 1 & 1 & 5 & 13 & 10 \\
\hline Direct violence . & 3 & 1 & 2 & 3 & 1 & 10 & 7 \\
\hline Motor accident . & 7 & 6 & 3 & 2 & 2 & 20 & 15 \\
\hline Blow inner side leg & - & - & - & 1 & - & 1 & 1 \\
\hline Total & 32 & 25 & 61 & 8 & 9 & 135 & 100 \\
\hline Percentage & 24 & 18 & 45 & 6 & 7 & & \\
\hline
\end{tabular}

TABLE III

Degree of Displacement Found in Each Type of InJury

\begin{tabular}{|c|c|c|c|}
\hline \multirow{2}{*}{$\begin{array}{l}\text { Type of } \\
\text { fracture }\end{array}$} & \multicolumn{3}{|c|}{ Degree of displacement } \\
\hline & Mild & Moderate & Severe \\
\hline $\mathbf{P}$ & 19 & 6 & 7 \\
\hline PL & 10 & 9 & 6 \\
\hline SL & 11 & 28 & 22 \\
\hline $\mathbf{S}$ & 7 & - & 1 \\
\hline Other . & 1 & 2 & 6 \\
\hline Total & 48 & 45 & 42 \\
\hline
\end{tabular}


Nature of the accident-This is shown in Table II. Slipping or stumbling accounted for forty-two (69 per cent) of the SL group and for sixty-two (46 per cent) of the total.

Classification-The material has been classified in three ways-by the "genetic" method of Lauge-Hansen, according to the initial degree of displacement, and according to the number of malleoli fractured.

Genetic Classification-The results are shown in Figure 16.

The distribution is in general conformity with the results of other published series (Vasli 1957, Klossner 1962). SL fractures form the largest group, although the proportion is rather lower than in other published work because in the present series there are not more women than men. Fractures in the S, PD and irregular groups were found entirely in men; of the fractures in the four main groups, twenty-one of the patients (17 per cent) had injuries in stages 1 and 2, while 105 ( 83 per cent) had injuries in stages 3 and 4.
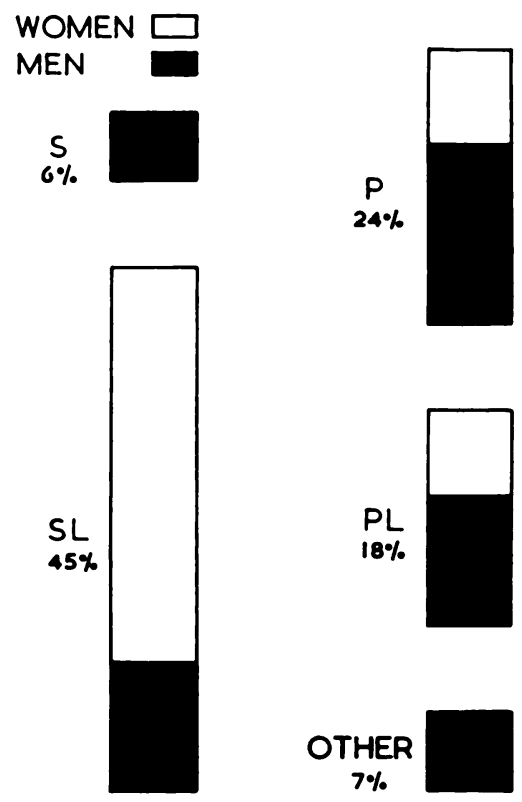

$7 \%$

Fig. 16

Figure 16-Classification of the material by the genetic method.

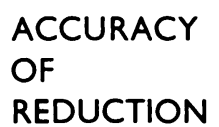

REDUCTION

ANATOMICAL

FAIR

POOR

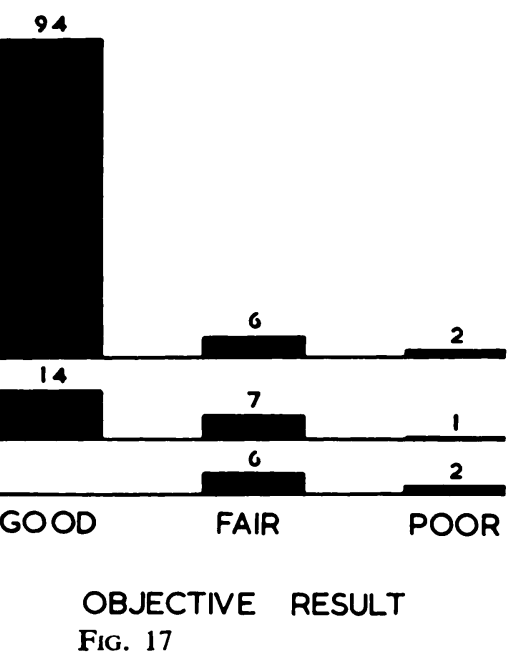

Figure 17-Objective results related to accuracy of reduction.

Classification according to initial degree of displacement-This has been done in order to obtain a general indication of the severity of the injuries. Three grades of displacement of the talus have been recognised: 1) Mild-displacement slight. 2) Moderate-talar displacement up to half the width of the ankle mortise. 3) Severe-displacement greater than above.

Moderate or severe displacement was present in 82 per cent of the SL type injuries and in 64 per cent of the total.

Classification according to the number of malleoli fractured-This information is included for the purpose of comparison with some earlier series. The analysis is shown in Table IV.

Compound fractures-Seven patients had compound fractures ( 5.2 per cent); three were in the PL group and the remainder were distributed evenly over the other four groups.

Associated injuries-Two patients had in addition sustained fractures of the same tibia that were treated by plate fixation and two other patients had fractures of the talus or calcaneus.

\section{METHOD OF TREATMENT}

Preliminary manipulation-A manipulation followed by the application of a plaster had been undertaken in twenty-five cases. This initial treatment was not a matter of policy but had 
been used in a number of patients transferred from other hospitals; it was also used as a temporary measure in severely displaced fractures, under morphine sedation, in order to protect the skin until operation could be undertaken.

Timing of operation-Operation was undertaken on the day of the accident in eighty patients and on the following day in twenty-four patients; thus 77 per cent of the operations were performed during the first forty-eight hours. In no instance was operation delayed beyond the tenth day.

Number of surgeons-One hundred and twenty-three patients were operated on by the authors, the remainder by three other surgeons.

TABLE IV

Classification by Number of Malleoli Fractured

\begin{tabular}{|c|c|c|c|c|c|c|}
\hline & & & & $\begin{array}{c}\text { Number of } \\
\text { ankles }\end{array}$ & Total & Percentage \\
\hline UNIMALLEOLAR & $\begin{array}{l}\text { Medial } \\
\text { Anterior tubercle }\end{array}$ & & . & $\begin{array}{r}23 \\
1\end{array}$ & 24 & 18 \\
\hline Bimalleolar & $\begin{array}{l}\text { Medial and lateral } \\
\text { Lateral and medial } \\
\text { Medial and posterio } \\
\text { Medial and anterior }\end{array}$ & nen & $\begin{array}{ll}\cdot & \cdot \\
\cdot & \cdot \\
\cdot & \cdot \\
\cdot & .\end{array}$ & $\begin{array}{r}60 \\
4 \\
1 \\
2\end{array}$ & 67 & 49 \\
\hline TRIMALLEOLAR & $\begin{array}{l}\text { Medial, lateral and } p \\
\text { Lateral, posterior an }\end{array}$ & eric & igament & $\begin{array}{r}37 \\
6\end{array}$ & 43 & 32 \\
\hline UNCLASSIFIED & & & & 1 & & \\
\hline
\end{tabular}

'Posterior' indicates a posterior fragment large enough to involve the articular surface.

Types of internal fixation used-Standard coarse thread screws and Burns or Sherman plates were used for most of the fractures; in a few instances it was necessary to use pins or hook plates. The type of fixation used in the three main fractures is shown in Tables V, VI and VII.

An anterior marginal fragment was fixed in place with a screw in three patients; the anterior tibial tubercle was similarly fixed in two patients; screw fixation of the syndesmosis was undertaken on two occasions.

Antibiotics - With the exception of compound fractures or where the skin had been abraded, antibiotics were not used.

Duration of post-operative exercises-The duration of the exercises in bed following the operation is shown in Table VIII.

It will be seen that the more severely injured ankles (PL and "other" groups) required exercises for a longer period in order to restore full movement.

Plaster immobilisation-After restoration of the ankle and foot movements a below-knee walking plaster was applied in 114 (84 per cent) of the patients to reduce the degree of incapacity and to prevent osteoporosis by allowing full weight bearing. The average periods of immobilisation for the different types of injuries are shown in Table IX.

In twenty-one patients, mostly young subjects in the $\mathrm{P}$ and PL groups, plaster immobilisation was not used.

Secondary operation-Five patients required secondary procedures: in four, revision of the operation was done and in one case amputation.

Removal of the internal fixation appliances-Screws or pins were removed in ten patients (7.4 per cent). In two patients screws were removed as a possible source of pain and in one 
instance for sepsis. In three patients screws were removed because of close proximity to joint surfaces. In the remaining four instances, all of them young subjects, pins were removed a few weeks after operation.

Complications. Sepsis-Eight patients developed superficial infection but required no treatment; all obtained good results. In one instance, infection was more serious but resolved after

TABLE V

Method of Fixation Used for Medial Malleolus

\begin{tabular}{|l|c|c|c|c|c|}
\hline & P & PL & SL & S & Other \\
\hline One screw. & 25 & 20 & 42 & 2 & 5 \\
\hline Two screws & 3 & 2 & 3 & 3 & 3 \\
\hline Pin . & 3 & 2 & 3 & 1 & - \\
\hline Hook plate & - & - & - & 1 & - \\
\hline Excised . & 1 & - & - & - & - \\
\hline No fixation & - & 1 & 3 & - & - \\
\hline
\end{tabular}

TABLE VI

Method of Fixation Used for Lateral Malleolus and Fibula

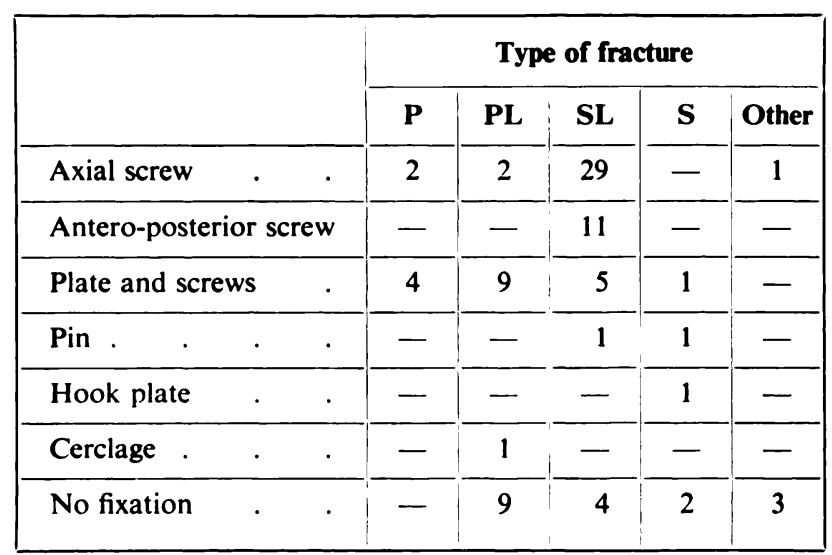

TABLE VII

Method of Fixation Used for Posterior Malleolus

\begin{tabular}{|c|c|c|c|c|c|}
\hline & \multicolumn{5}{|c|}{ Type of fracture } \\
\hline & $\mathbf{P}$ & $\mathbf{P L}$ & SL & $\mathbf{S}$ & Other \\
\hline One screw & - & - & - & - & 2 \\
\hline Two screws. & 1 & - & 8 & - & - \\
\hline Three screws & - & 一 & 2 & - & - \\
\hline
\end{tabular}

removal of the internal fixation appliance. One of the instances of sepsis was in a compound fracture; there was no infection in the remaining six compound fractures.

Delayed union-There was no instance of non-union; in one of the fractures, referred to in the discussion, union was delayed.

VOL 47 B, NO. 4, NOVEMBER 1965 
Amputation-One patient, who had sustained an SL4 fracture complicated by vascular impairment, required amputation at four weeks.

Deaths-Two patients died: one aged eighty-five years with a PL fracture at five weeks, the other aged sixty-four years with a $P$ fracture at five months. In each instance the cause of death was pulmonary embolism.

These two patients and the patient whose leg was amputated have been excluded from further consideration.

\section{RESULTS}

Radiographic criteria of reduction-It has been felt necessary to observe strict criteria of reduction and these accord with those employed by Magnusson (1944), by Vasli (1957) and by Klossner (1962). The gradings are shown in Table X.

TABLE VIII

Duration of Period of Exercises after Operation

\begin{tabular}{|c|c|}
\hline Type of fracture & $\begin{array}{c}\text { Duration of exercise period } \\
\text { (weeks) }\end{array}$ \\
\hline P & $2 \cdot 9$ \\
\hline PL & $3 \cdot 7$ \\
\hline SL & $3 \cdot 0$ \\
\hline S & $2 \cdot 4$ \\
\hline Other & $4 \cdot 3$ \\
\hline Average & $3 \cdot 0$ \\
\hline
\end{tabular}

TABLE IX

Duration of Plaster ImMobilisation

\begin{tabular}{|c|c|}
\hline Type of fracture & $\begin{array}{c}\text { Duration of immobilisation } \\
\text { (weeks) }\end{array}$ \\
\hline P & $5 \cdot 0$ \\
\hline PL & $5 \cdot 3$ \\
\hline SL & $5 \cdot 2$ \\
\hline S & $4 \cdot 5$ \\
\hline Other & $6 \cdot 3$ \\
\hline
\end{tabular}

Accuracy of reduction as judged by the post-operative radiograph-Table XI shows the standard of reduction obtained for each type of fracture. In the $\mathrm{P}$ and $\mathrm{S}$ groups anatomical reduction was regularly achieved; the PL and SL injuries showed a proportion of less accurate reduction; in the PD and irregular groups of injuries the general standard obtained was only fair.

Table XII shows the standard of reduction according to the initial degree of displacement of the fractures.

Over the whole series anatomical reduction was obtained in 77.2 per cent of the patients; the reduction was fair in 16.7 per cent and poor in 6.1 per cent.

Clinical results. Objective criteria-The criteria used are again those of Magnusson (1944), Vasli (1957) and Klossner (1962) and are close to those of Kristensen (1956), Jones and Neal (1962) and, with slight modification of terminology, those of Braunstein and Wade (1959). 
The objective criteria are set out below. Good-Ankle and foot movements at least threequarters normal, trivial swelling, normal gait; Fair-Ankle and foot movements at least half normal, small amount of swelling, normal gait; Poor-Ankle and foot movements less than half normal, swelling, any visible deformity of ankle or foot, limp.

TABLE X

Radiographic Criteria of Reduction

\begin{tabular}{l} 
ANATOMICAL \\
No medial or lateral displacement of the medial and lateral malleoli \\
No angulation \\
Not more than 1 millimetre longitudinal displacement of the medial and lateral malleoli \\
Not more than 2 millimetres proximal displacement of a large posterior fragment \\
No displacement of the talus \\
FAIR \\
No medial or lateral displacement of the medial and lateral malleoli \\
No angulation \\
$2-5$ millimetres posterior displacement of the lateral malleolus \\
$2-5$ millimetres proximal displacement of a large posterior fragment \\
No displacement of the talus \\
\hline PoOR \\
Any medial or lateral displacement of the medial and lateral malleoli \\
More than 5 millimetres posterior displacement of the lateral malleolus or more than \\
Any residual displacement of the talus
\end{tabular}

TABLE XI

Standard of Reduction Obtained for Each Type of Fracture

\begin{tabular}{|l|c|c|c|c|}
\hline \multirow{2}{*}{ Type of fracture } & \multicolumn{3}{|c|}{ Standard of reduction } \\
\cline { 3 - 5 } & Anatomical & Fair & Poor \\
\hline $\mathrm{P}$ & $\cdot$ & 27 & 4 & - \\
\hline $\mathrm{PL} \cdot$ & $\cdot$ & 18 & 4 & 2 \\
\hline $\mathrm{SL} \cdot$ & $\cdot$ & 47 & 9 & 4 \\
\hline $\mathrm{S} \cdot \cdot$ & 8 & - & - \\
\hline Other. & $\cdot$ & 2 & 5 & 2 \\
\hline Total . & $\cdot$ & 102 & 22 & 8 \\
\hline Percentage . & $77 \cdot 2$ & $16 \cdot 7$ & $6 \cdot 1$ \\
\hline
\end{tabular}

The objective results are shown in relation to the type of fracture (Table XIII) and in relation to the accuracy of reduction (Fig. 17).

Subjective criteria-All patients were questioned as to the presence of pain or aching or a sensation of stiffness, and any disability. The grading used is given below. Good-Complete 
recovery apart from possible slight aching after use; Fair-Aching during use, slight stiffness (not enough to interfere with work), ability to walk not seriously impaired; Poor-Any serious impairment of ability to work or walk, pain.

The results agree closely with the objective results and it is not felt that they merit a separate table. In 117 patients ( 89 per cent) the objective and subjective results were identical. Three patients whose objective results were fair had good subjective results. Nine ankles objectively good were subjectively fair; of two ankles objectively graded poor, the subjective result in one instance was good, and in the other fair.

TABLE XII

Standard of Reduction Related to Initial Degree of Displacement

\begin{tabular}{|l|c|c|c|}
\hline $\begin{array}{c}\text { Initial } \\
\text { displacement }\end{array}$ & \multicolumn{3}{|c|}{ Standard of reduction } \\
\cline { 2 - 4 }$\cdot$ Anatomical & Fair & Poor \\
\hline Mild $\cdot$ & 42 & 6 & - \\
\hline Moderate & 33 & 6 & 4 \\
\hline Severe . & 27 & 10 & 4 \\
\hline Total $\cdot$ & 102 & 22 & 8 \\
Percentage $\cdot$ & $77 \cdot 3$ & $16 \cdot 7$ & 6 \\
\hline
\end{tabular}

TABLE XIII

Objective Results Related to Type of Fracture

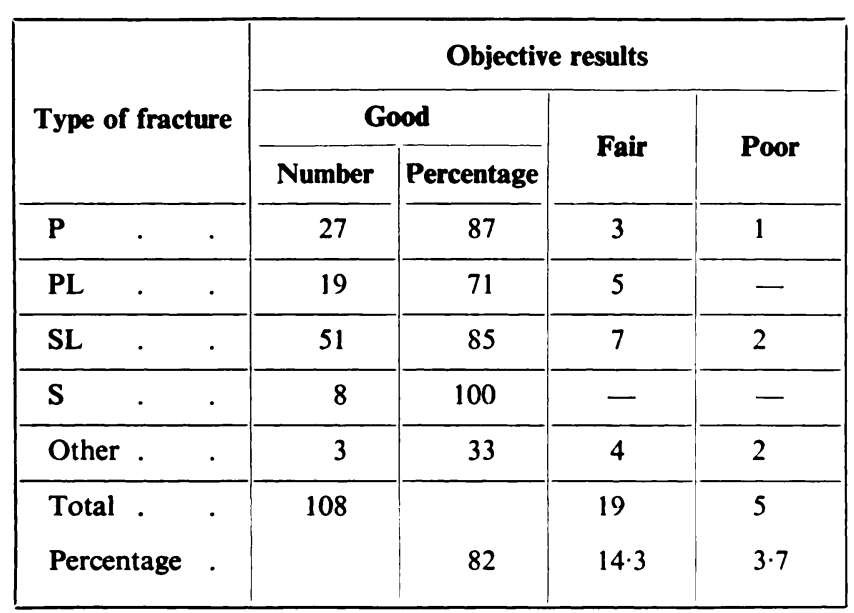

\section{DISCUSSION}

Diagnosis of injuries to the ankle-Bonnin (1950), Kleiger (1954) and Rose (1962) pointed out that little reliance can be placed on the patient's interpretation of how the ankle was injured because he usually has little idea of the forces involved. It is more satisfactory to take account only of the information obtained from the radiographic and clinical examinations.

Correctly centred radiographs are essential, and of special importance is the anteroposterior view with the limb in slight medial rotation (Bonnin 1950), which by displaying the medial clear space exposes any lack of congruity between the talar and tibial articular surfaces. Special radiographic projections in order to show the syndesmosis have not been used, because the presence of diastasis may be inferred by reference to the Lauge-Hansen classification; 
in addition the difficulties in the diagnosis of diastasis by radiography have teen well discussed (Magnusson 1944, Close 1956, Iselin and de Vellis 1961, Rose 1962, Scott 1962). The need for careful scrutiny of radiographs in order to detect the presence of small shell-shaped avulsed fragments indicating ligamentous injury has already been stressed. Examination for areas of tenderness over ligaments will indicate the need for strain films to reveal instability of the joint. as shown in Figures 18, 19 and 20. In this connection an ankle injury which may

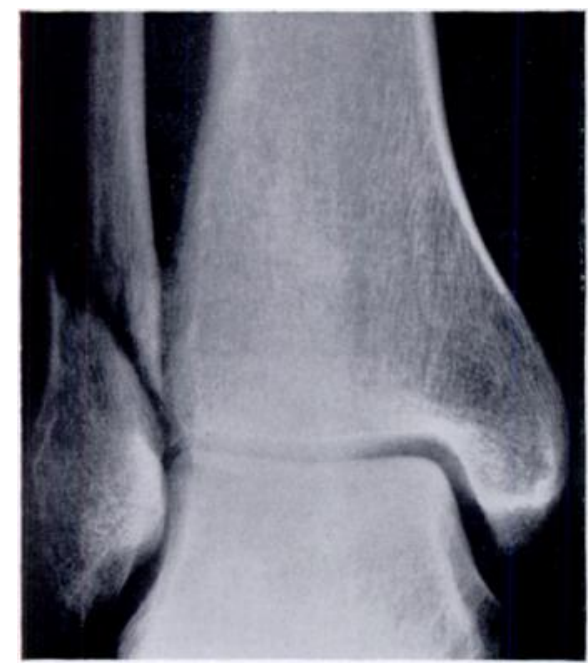

Fig. 18

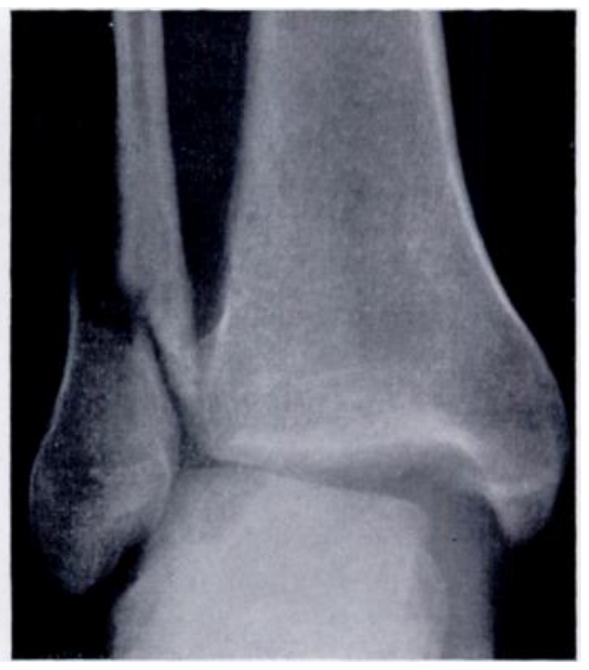

FiG. 19

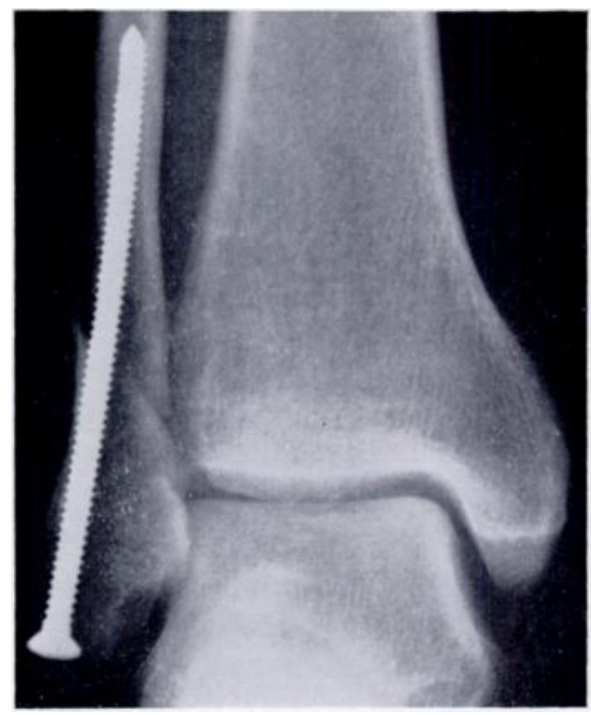

Fig. 20

appear to be of SL2 grade (not involving displacement of the talus in the ankle mortise) may in fact be of SL4 grade in which the dislocation has undergone spontaneous reduction before a radiographic examination is made; if that is so, the degree of general swelling of the ankle and the tenderness over the ruptured medial ligament will indicate that there has been a more serious injury. Injuries to the calcaneo-fibular ligament which are usually unassociated with fracture of the ankle have not been considered. 
The standard of reduction required-Fractures at the ankle being articular and in a weightbearing extremity require accurate reduction if residual pain and disability are to be avoided and the incidence of arthritis is to be reduced (Lambotte 1907, Lane 1914, Lewis and Graham 1940, de Marneffe 1955, Jergesen 1959). In particular, residual sideways displacement of the medial and lateral malleoli, by allowing displacement and lack of congruity of the talus in the ankle mortise, must be avoided. In fracture of the medial malleolus displacement or angulation in any direction may be expected to impair the result; in the case of the lateral malleolus it is held (Vasli 1957) that posterior displacement of up to two millimetres is compatible with a good result, and displacement of up to five millimetres compatible with a fair result. In the case of the posterior malleolus, if more than a third of the articular surface is broken off exact reduction is essential; if between a third and a quarter of the articular surface is broken off the standards relating to the lateral malleolus apply; the position of posterior fragments involving less than a quarter of the articular surface can be ignored (Nelson and Jensen 1940; Vasli 1957; Bergkvist, Hultengren, Lindholm and Lindvall 1958; Klossner 1962). It seems clear from the results of these authors and also from the present series that the quality of the clinical outcome varies in relation to the accuracy of the reduction as shown in Figure 17. The requirements have been summarised by Smith (1956): "In fractures of the ankle only the slightest variations from normal anatomy are compatible with good function of the joint."

The closed method. Difficulty in achieving and maintaining accurate reduction-Accurate reduction by closed manipulation may be obtained in a number of low bimalleolar fractures of the SL type in which the talus and the two malleoli move together-the "bloc astragalobimalleolaire" of Iselin and de Vellis (1961). However, manipulation offers little control over large posterior tibial fragments and in addition, solitary displaced fractures of the medial malleolus (stage 1 of the P and PL groups) cause difficulty, in that forward displacement of the malleolus must usually be accepted. Difficulty in maintaining the initial reduction is discussed by many authors of whom Cox and Laxson (1952), Mitchell and Fleming (1959), and Cedell and Wiberg (1962) may be mentioned. In the series reported by Braunstein and Wade (1959) of fifty-seven patients whose ankle injuries had been treated by closed reduction, twenty-eight required a second manipulation, and eight a third or fourth manipulation. These authors comment on the difficulty in maintaining the position by plaster splintage during the first few weeks as the oedema subsides.

Extent of immobilisation necessary-Assuming that an adequate closed reduction can be obtained, the patient who has sustained a displaced bimalleolar or trimalleolar fracture should have the injured limb immobilised in a plaster for ten to twelve weeks. During the first half of this period the plaster should extend above the knee, and weight bearing should be avoided. Uninterrupted immobilisation for this period after a severe ankle injury results in organisation of the traumatic exudate so that ankle and foot movements may be imperfectly restored; in addition, this state is achieved only after a long period of rehabilitation and incapacity. A further risk when weight bearing is avoided for long is the development of osteoporosis which may only resolve after many months. Resolution may be incomplete, particularly in relatively inactive persons, so that there is permanent pain and swelling.

Risk of malunion and residual subluxation - Should the congruity of the ankle not be maintained, resulting in malunion, disability is inevitable; attempts at correction are then difficult (Bonnin 1950), and when successful as the result of operation (Trethowan 1926), are liable to be followed by early degenerative arthritis (MacKinnon 1928, Speed and Boyd 1936).

Risk of non-union-Non-union of the medial malleolus is also a definite hazard. Although soft-tissue interposition is often described as periosteal in origin, in this series it was found that the material was usually derived from the transverse retinacular fibres which have been described by Muller (1945) as an aponeurotic curtain. Material of this nature was present in more than half of the patients in this series, a similar proportion being reported by Burgess (1944), whereas Meekison (1945) found interposition in all of his patients. Interposition of 
the posterior tibial tendon has been reported as a reason for failure of reduction of the medial malleolus (Coonrad and Bugg 1954) but was not found in this series. Non-union of the medial malleolus is one of the common causes of instability of the ankle (Burgess 1944). It is also liable to give pain or to cause tenosynovitis around the tibialis posterior (Banks 1949). If non-union is present the outcome may be satisfactory if only the tip of the bone is involved; rarely is this so if the fracture is at the level of the joint line (Jones and Neal 1962) unless there is a very firm fibrous union (Klossner 1962). Magnusson (1944) considered the incidence of non-union of the medial malleolus in conservatively treated fractures to be 10 to 15 per cent; recent series of conservatively managed fractures show incidences of 12 per cent (Biström 1952), 7 per cent (Jones and Neal 1962) and 8 per cent (Klossner 1962). Treatment by bone grafting may then be possible and a satisfactory method appears to be that described by Banks (1949), although inevitably the patient has to undergo a further operation followed by periods of plaster immobilisation and rehabilitation causing extended incapacity.

Limited open reduction followed by manipulation and the application of a plaster-A method commonly used after failure of closed reduction is that of internal fixation of the medial malleolus followed by manipulative reduction of the other fragments. The medial malleolus is thereby used as a fixed point for realignment, after which plaster is applied. It is a definite improvement over the closed method since the general alignment of the ankle is usually more

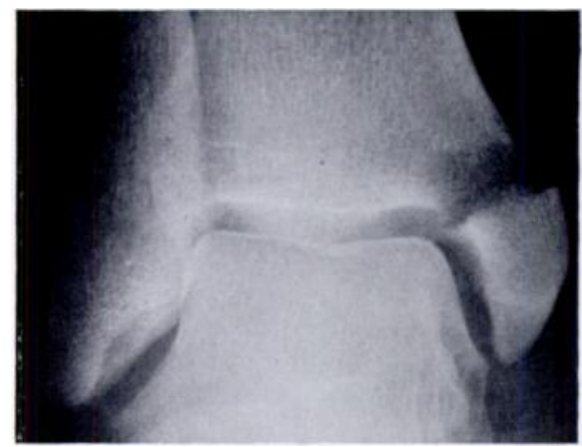

FIG. 21

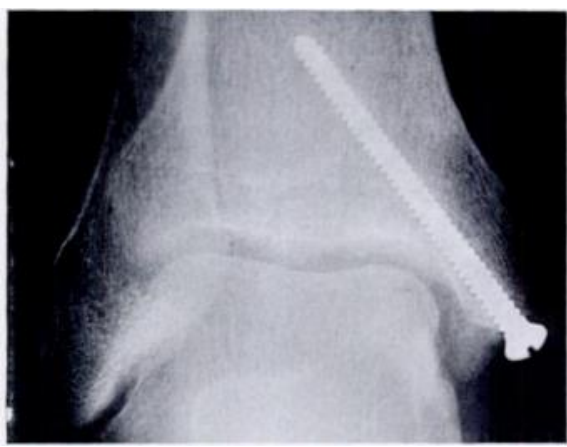

Fig. 22

Radiographs showing screw fixation of isolated fracture of medial malleolus. P1 type.

satisfactory and non-union of the medial malleolus is eliminated. A plaster extending above the knee, which would increase the temporary disability, is usually not employed although immobilisation is frequently continued for eight or more weeks, so that the period of rehabilitation has to be prolonged.

Rigid internal fixation followed by early exercises-This is the method advocated in this paper. Isolated fractures of the medial malleolus, unless undisplaced, are treated by open reduction and internal fixation (Figs. 21 and 22), followed by early joint movement. In the more severe injuries, if full reduction is to be maintained and early exercises are to be encouraged, more than one of the fractures must usually be fixed in order to make the ankle stable without external support. The advantages of this method of treatment, which has been employed in this series, are as follows. Firstly, accurate reduction is usually achieved and maintained. Secondly, active exercises, practised regularly in bed during the healing of the wound, prevent organisation of the traumatic exudate which otherwise may cause dense adhesions. The evacuation of the haemarthrosis at the time of the operation is also of value in this connection. When a full range of ankle and foot movements has been restored, a below-knee plaster is applied in order to permit full weight bearing which reduces the disability and materially reduces osteoporosis.

Fixation of medial malleolar fractures-Accurate fixation of the fractures of the medial malleolus, which always involve the articular surface of the joint, is considered essential, and 
in this series the fragment was the first to be dealt with, a screw of not less than one and three-quarter inches in length being used. There is then no danger of redisplacement or non-union, the fracture line not infrequently teing invisible on the radiograph taken after operation. The need for a screw of adequate length has been stressed by a number of authors (Muller 1945, Mitchell and Fleming 1959, Jergesen 1959); large fragments may require the use of two screws (fourteen patients in this series). Where there has been comminution (on one occasion in this series) the hook plate described by Zuelzer (1951) may te used. Stainless steel pins two millimetres in diameter have been used on a few occasions for small fragments or in young subjects, in order to avoid growth arrest at the epiphysial line.

Fixation of lateral malleolar or fibular fractures-Reduction of the medial side of the joint frequently restores the lateral malleolus to acceptable position (Muller 1945, Braunstein and Wade 1959) but it should be emphasised that this is not always achieved (Cedell and Wiberg 1962). Rotational deformity in particular may persist, impair the function of the joint and predispose to arthritis. There is also the possibility of residual displacement of the talus if the medial ligament has been damaged, in addition to fracture of the medial malleolus (Close 1956) (Figs. 23 and 24). Nevertheless, in the earlier years of this series there was a tendency to rely

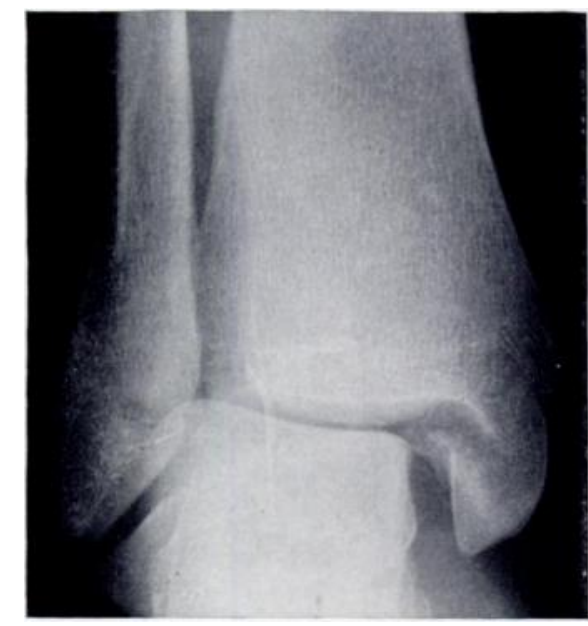

Fig. 23

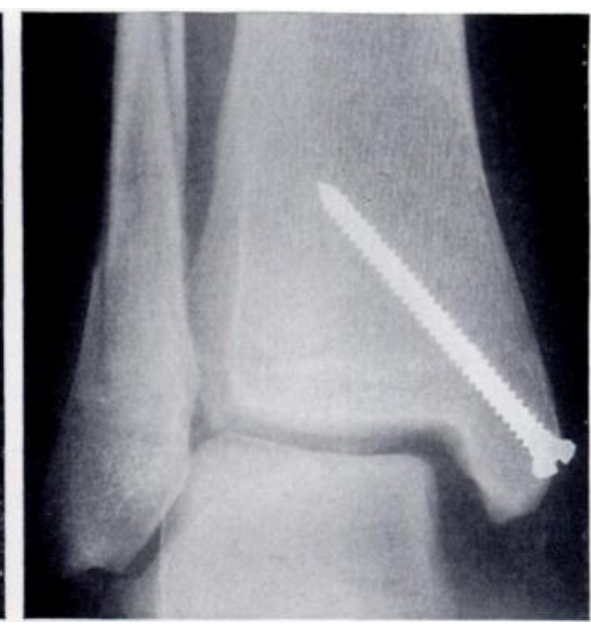

FIG. 24

Radiographs showing residual subluxation after accurate fixation of medial malleolusassociated injury of the medial ligament.

on fixation of the medial malleolus alone. It is now felt that full reduction and stabilisation of the fibula is necessary both for the reasons given and because an unsupported fracture at the outer side of the joint may inhibit by pain the rapid return of movement. Finally, if the fibular fracture is not fixed there may be delayed or non-union (Cox and Laxson 1952).

Fixation of fibular fractures may be achieved in a number of ways. In this series the low SL type of fracture has usually been stabilised by an axial screw, as also used by Jergesen (1959), and by Mitchell and Fleming (1959) and Lamare and Scheer (1960). This screw should be three or four inches in length and can be quickly and easily inserted at the tip of the bone just lateral to the ligamentous attachment (Figs. 4 and 20). The Rush pin used by some surgeons is less satisfactory because it provides less firm fixation and is liable to displace. An alternative method which has been used in this series consists of one or two short anteroposterior screws traversing the fracture (Figs. 25 to 28 and 29 to 32). An oblique screw from the lower fibular fragment into the tibia (Burgess 1944) is considered to interfere unnecessarily with the syndesmosis. Fractures of the $\mathrm{S}$ and $\mathrm{P}$ types are also usually suitable for fixation with an axial screw (Figs. 10 to 13), but fractures of the fibular shaft (PL type) are best stabilised by a short plate and four screws (Figs. 6 to 9). Wiring of the fibula (cerclage) was extensively 
employed in Vasli's series, but the method in general has been strongly criticised (Charnley 1957) and in this series it was used only once: a year after operation the fracture was ununited because of avascular change, but union was observed in radiographs taken four years later.

Fixation of the posterior malleolar fracture-We have adopted the generally accepted view (Vasli 1957, Klossner 1962) that fragments involving less than a third of the articular surface do not require internal fixation unless they are much displaced. It has been found that more than one screw is frequently needed to fix the fragments securely (nine out of thirteen in this series) (Figs. 29 to 32). The postero-lateral incision described by Henry (1945) has been used and found to be satisfactory.

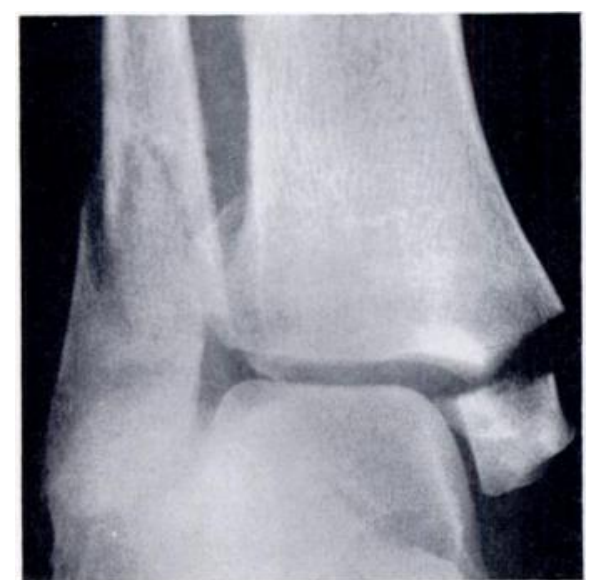

Fig. 25

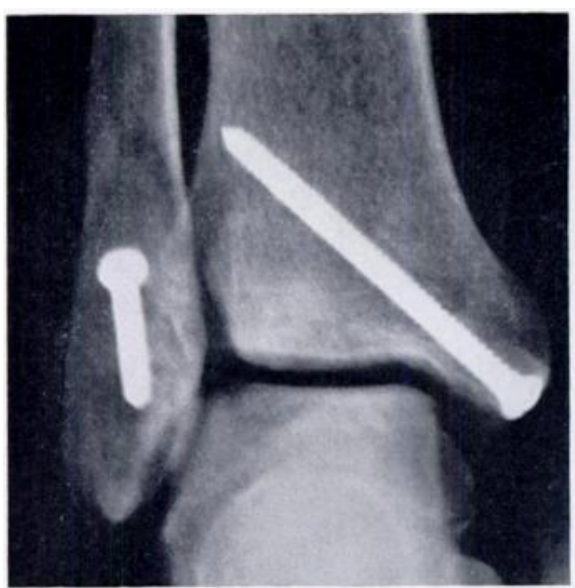

FIG. 27

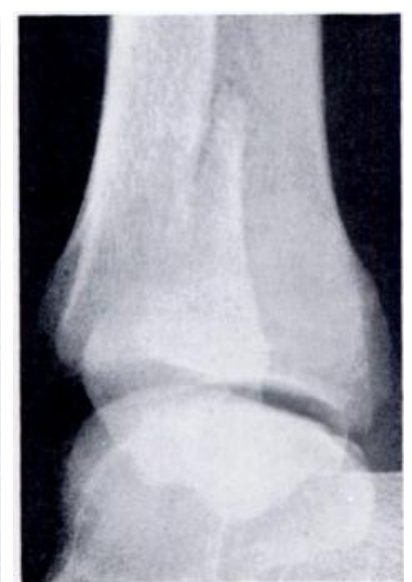

Fig. 26

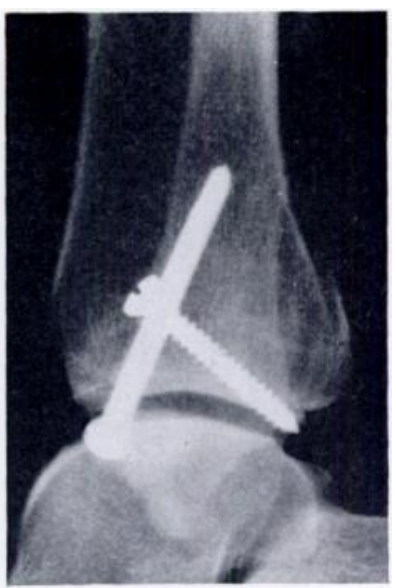

FIG. 28

Radiographs showing SL4 fracture: fixation of fibula by antero-posterior screw.

Compression fractures-In severe injuries caused by a fall from a height there is frequently extensive comminution and displacement (Figs. 33 to 36). Although anatomical reduction is not possible, the position may be much improved by a careful operation and sound fixation can be achieved, so as to give the benefits of early joint movement. The patient whose radiographs are shown here was reviewed six years after his accident when he had little discomfort or impairment of function.

Diastasis-This subject has been widely explored in medical writings for more than a century. Until recently diastasis has been held to imply only actual separation of the two bones of the leg, commonly in association with a fracture of the shaft of the fibula. When the distal 
part of the fibular shaft has retained its connection with the tibia, diastasis has been held to be absent no matter how great a degree of displacement of the lateral malleolus (and consequent luxation of the talus) may be present. In low bimalleolar and trimalleolar fractures (SL fractures) which form the largest group in a series, it is clearly unprofitable to speculate concerning the presence or absence of displacement of the fibular shaft (referred to in this

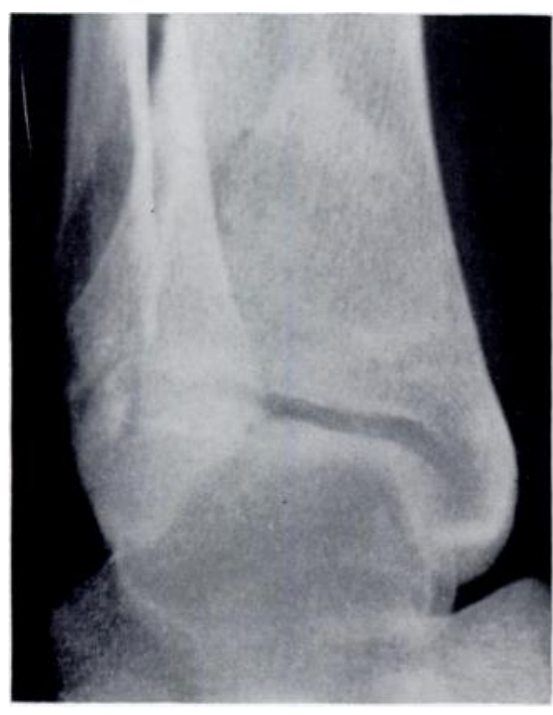

FIG. 29

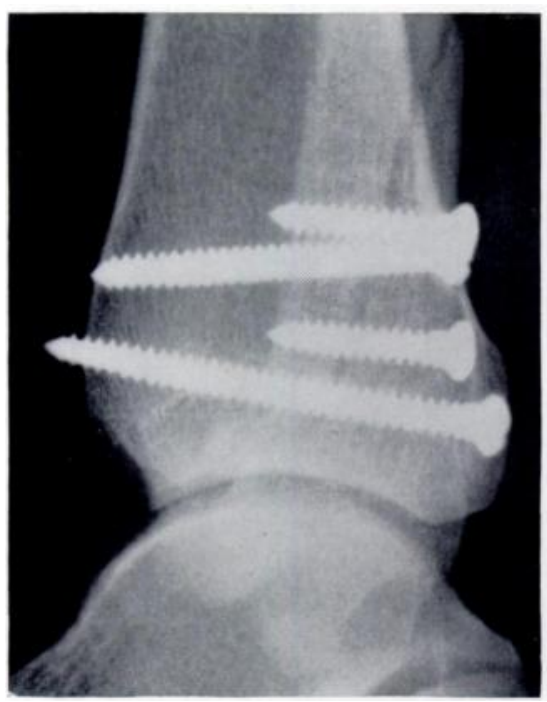

Fig. 31

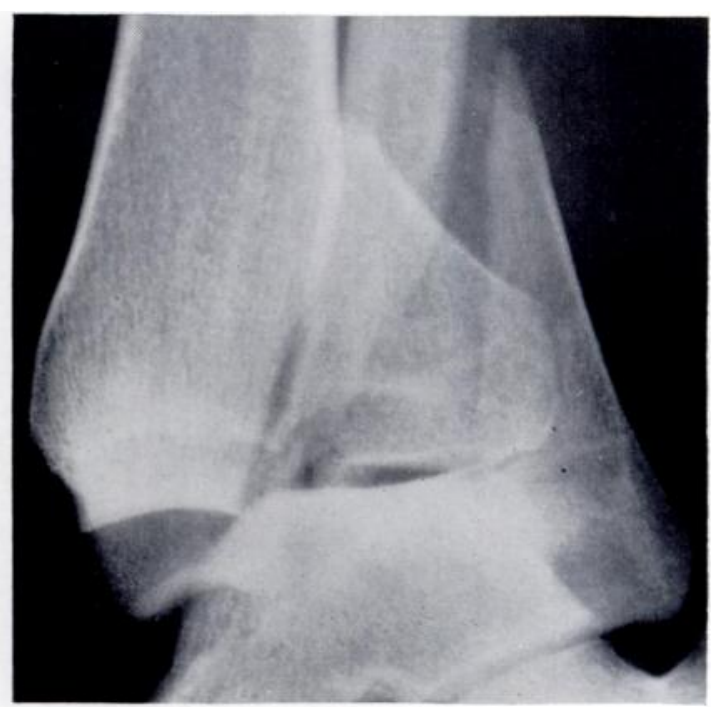

FIG. 30

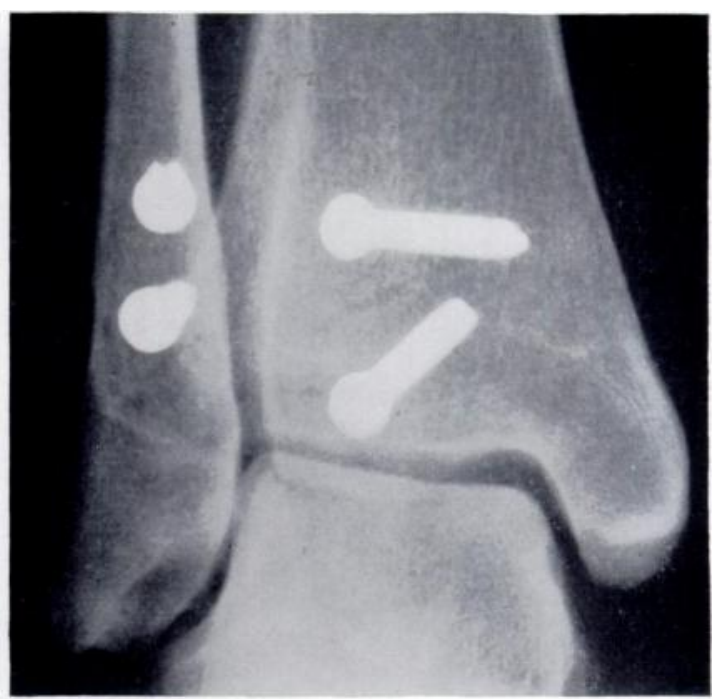

FIG. 32

Radiographs showing SL4 fracture: firm fixation of a large posterior fragment by two screws; fibula fixed by two antero-posterior screws.

paper as "classical diastasis ") in the presence of an unstable fracture of the lateral malleolus which allows uncontrolled displacement of the talus. The importance of instability of the lateral malleolus in this type of fracture has been discussed most recently by Iselin and de Vellis (1961) who introduced the term " diastasis intraperonière "-that is, diastasis between the two fragments of the fibula (intraosseous diastasis). Although Kleiger (1954) introduced the term "lateral ankle instability" when discussing fractures of this type, it is felt by the 
present writers that this could with advantage be used to embrace both types of displacement (shown in Figs. 37 and 38) because it emphasises what is important.

Classical diastasis has previously been considered of great importance and consequently diagnosis of the displacement by both clinical and radiographic methods has been emphasised

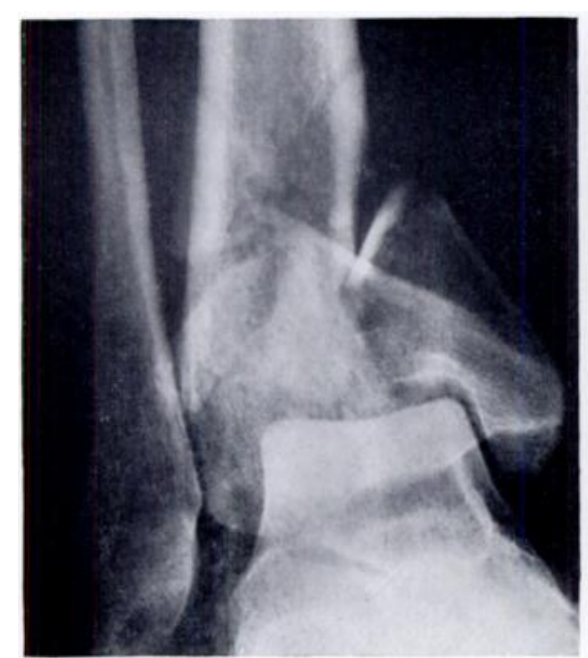

Fig. 33

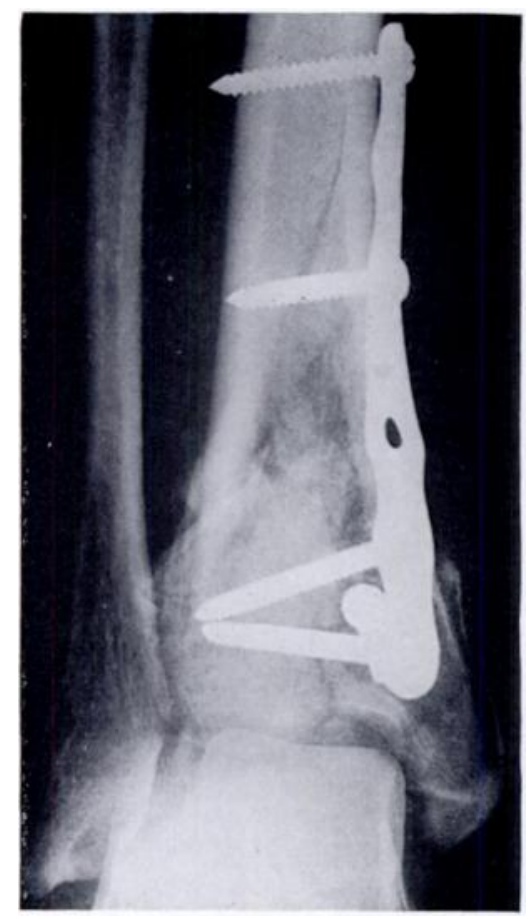

FIG. 35

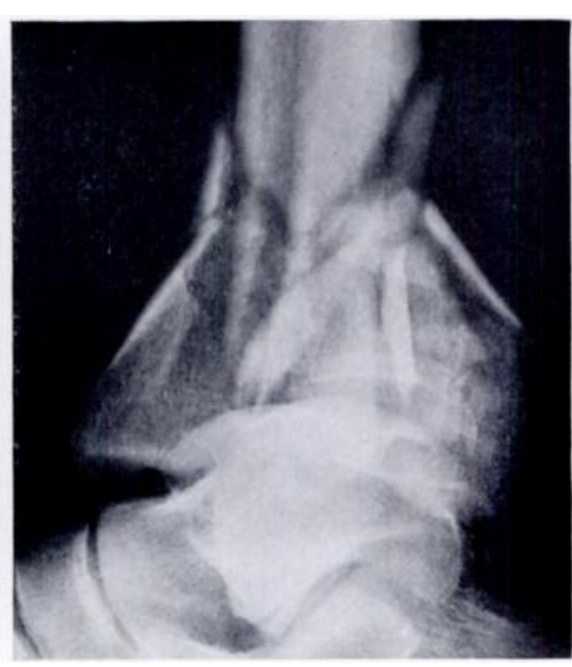

FIG. 34

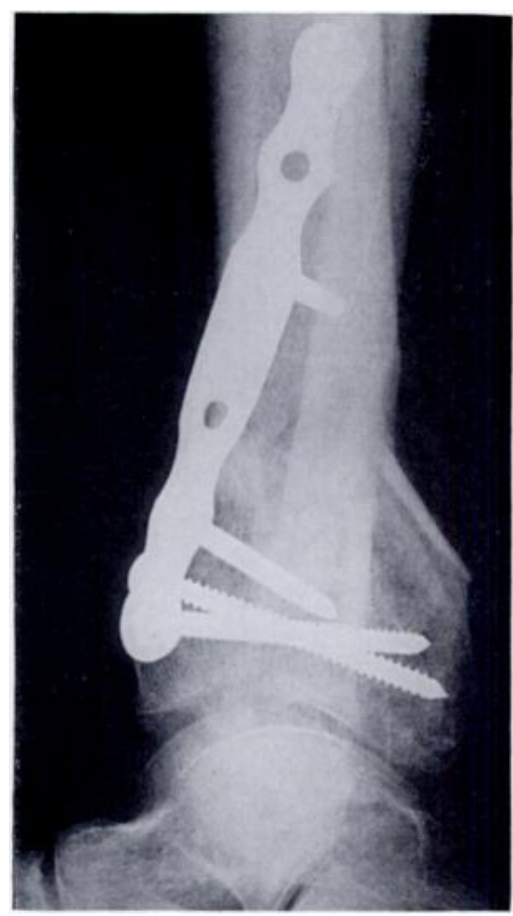

FIG. 36

Radiographs showing comminuted compression injury and method of internal fixation.

because it was felt that special measures were frequently required for its correction. Close (1956) showed, however, that section of the inferior tibio-fibular ligaments and interosseous membrane permitted only a small amount of separation at this joint if the fibula and medial malleolus (or medial ligament) remained intact. He also showed that if injuries of the latter 
bones were reduced and stabilised (either by external or internal fixation) the diastasis also was reduced and maintained in position. Classical diastasis is found in the PL3 and 4 fractures and in the series presented here the more recent fractures were treated by plating of the fibula (nine instances) in association with screw fixation of the medial malleolus (Figs. 8 and 9).

Previously many writers have regarded internal fixation of the syndesmosis as an essential part of the treatment in classical diastasis (Darrach 1942, Burgess 1944, Mayer 1956, Vasli 1957). Most writers use a screw although the technique differs. Cox and Laxson (1952), Vasli (1957) and Perkins (1958) advised that the screw should be inserted horizontally, and although Vasli reported satisfactory results, Cox and Laxson described angulation of the fibular fragment. Burgess (1944), Bonnin (1950), Mitchell and Fleming (1959), Klossner (1962) and Scott (1962) recommended that the screw should be oblique, and Klossner referred also to tilting of the fibula if the screw were horizontal. Mayer (1956) used a bolt across the syndesmosis supplemented by Zueltzer plates embracing the malleoli.

Apart from the doubt as to whether internal fixation of the syndesmosis is often necessary the method is not without grave disadvantages. The fibula must be accurately reduced before

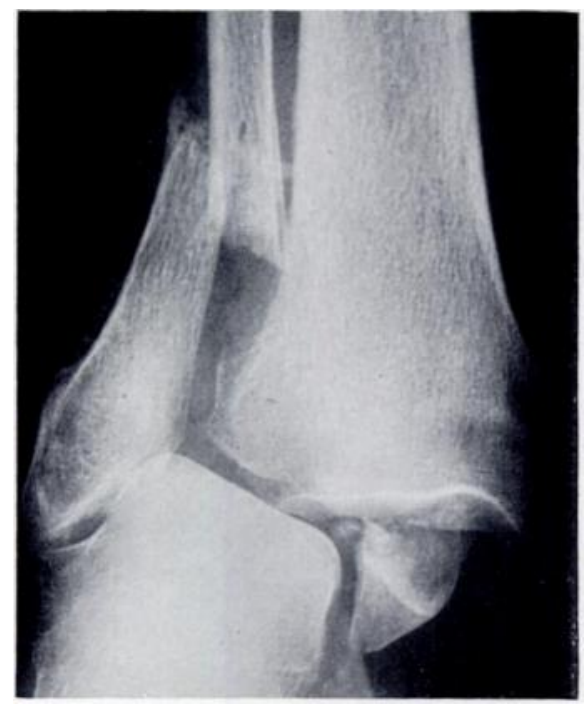

Fig. 37

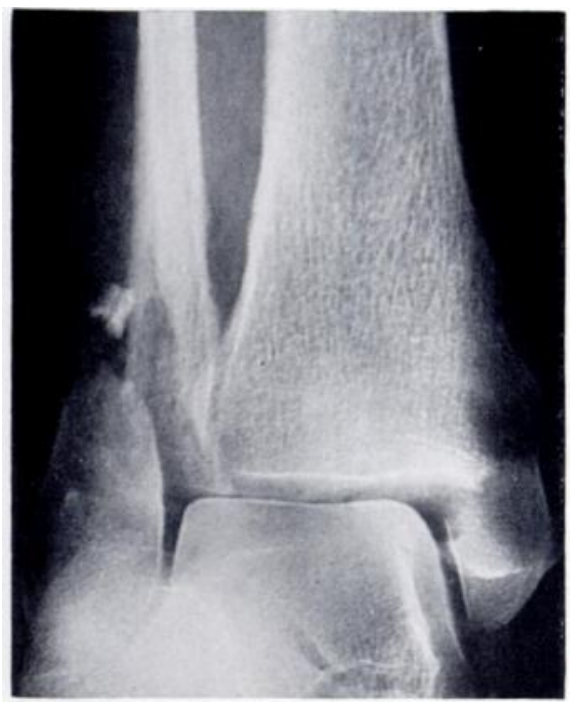

FiG. 38

Figure 37-Radiograph showing classical diastasis (PL4 fracture). Figure 38-Radiograph showing intraosseous diastasis (SL4 fracture).

fixation and it is difficult to avoid a little rotation or other displacement which would impair the ankle movements and predispose to arthritis. Charnley (1957) and Klossner (1962) referred to undue tightening of the screw, and the degree of tightening may be difficult to assess. Cox and Laxson (1952), Close (1956), Braunstein and Wade (1959) and Jergesen (1959) referred to the likelihood of breakage or loosening of the screw if it were not removed at a later operation. Bonnin (1950) also described persisting pain like a chronic sprain at the syndesmosis after removal of the screw. He also stated that if the screw were left in position it might cause a "wooden feeling" in the ankle or even limit dorsiflexion.

It seems, therefore, that internal fixation of the diastasis should not be undertaken lightly. In the present series it was done in only two instances, and even in these cases was later regarded as unnecessary.

The authors consider that it is important to take an antero-posterior radiograph after plating of the fibula and before completing the operation if the medial ligament has been ruptured, because the ligament may be turned into the joint and be obstructing full reduction 
(Figs. 39 and 40); in that case the ligament is replaced and spontaneous reduction is obtained. The usual régime is continued after operation.

Although classical diastasis occurred in twenty-four patients in this series it was not always visible on the plain radiograph although its presence could be deduced from a consideration of the Lauge-Hansen genetic classification, and its reduction was maintained by internal fixation of the associated fractures as described above. Healing of the syndesmosis was then achieved and the fibula remained free to divaricate slightly from the tibia, which is the normal state (Close 1956), and also to rotate in its long axis as confirmed by Grath (1960).

Intraosseous diastasis (" diastasis intraperonière ") is present in all SL4 fractures (40 per cent of this series). It is considered that this spiral fracture of the lateral malleolus should be stabilised by an axial screw. Fixation of the fibula to the tibia, as recommended by Burgess (1944) and Close (1956) is considered to be contra-indicated because it involves unnecessary interference with the syndesmosis with all the disadvantages referred to above.

The timing of the operation-Although Vasli (1957) considered that operation should be delayed in order to allow the soft-tissue reaction to settle, and that wound healing was then

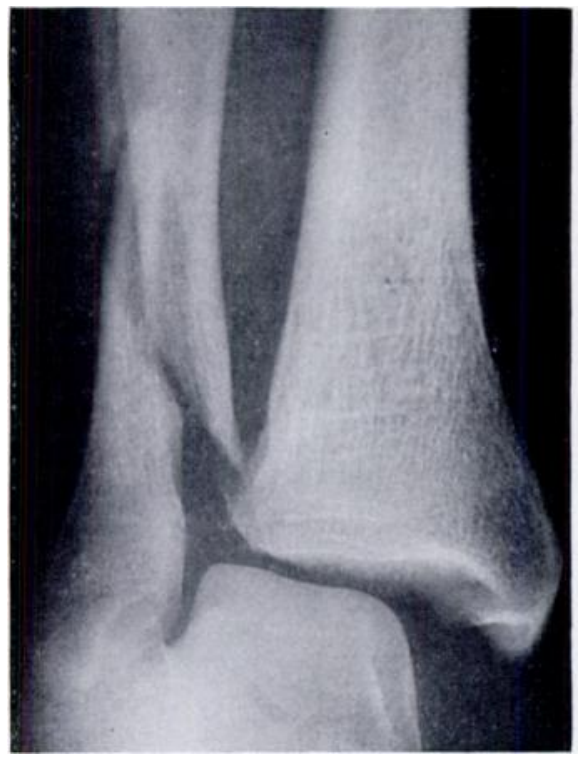

FIG. 39

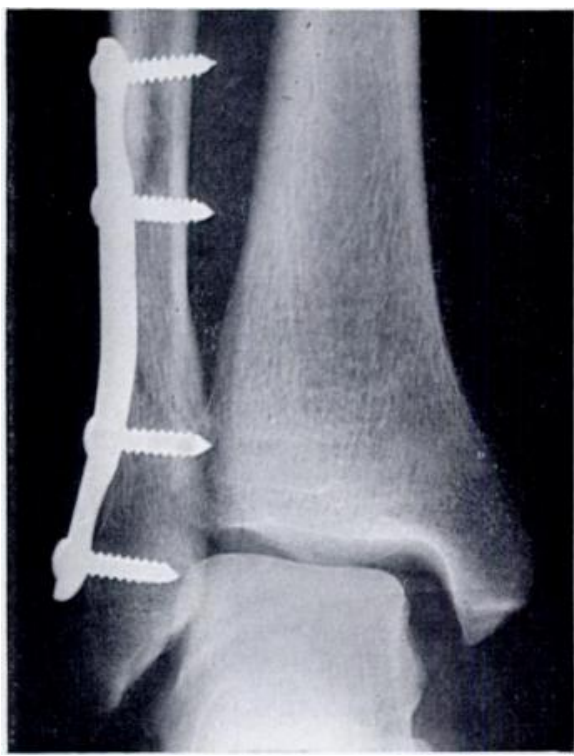

Fig. 40

Radiographs showing classical diastasis in a PL4 fracture: residual subluxation after plating caused by inturned deltoid ligament.

more satisfactory, Klossner (1962) recommended operation as soon as possible after injury because he did not find that this caused less satisfactory wound healing. This is the experience of the present writers, most of the operations in this series having been undertaken without delay. The conditions at the site of injury are more favourable to operation at this time because the fractures are more easily reduced before there has been organisation of the traumatic exudate. This view was advocated strongly by Murray (1944) in relation to the open treatment of fractures, and also by McLaughlin and Ryder (1949). When early operation is undertaken, any laceration or abrasion of the skin, which might become septic if left without thorough treatment, can be dealt with at the time of the operation so as to ensure healing. If open operation on ankle fractures is not possible on the day of the accident, then it is essential to bandage the ankle firmly over wool and to apply a plaster splint; in addition, the foot of the bed should be elevated. Under these conditions blistering of the skin, which would contra-indicate open operation, may be avoided. 
Technique of operation-A pneumatic tourniquet is used.

Medial malleolus - Either a curved incision just behind the medial malleolus or a straight one over the bone have been found satisfactory. The fracture surfaces are exposed and cleared after tilting the medial malleolus outwards. A seven-sixty-fourths inch twist drill is then entered near the apex of the medial malleolus and its emergence in the centre of the distal fracture surface is confirmed; the fracture is then accurately reduced and stabilised by two towel clips. The drill is then continued for one and a half to two inches into the cancellous bone of the tibia. The distal fragment is then over-drilled using a nine-sixty-fourths inch drill followed by insertion and tightening of a coarse-threaded screw not less than one and three-quarter inches long.

Lateral malleolus and fibular shaft-A straight incision centred over the fracture is satisfactory. The fracture is then reduced. In shaft fractures it is fixed by a three-inch plate and four screws, and in lateral malleolar fractures by an axial screw.

Posterior fragment-The postero-lateral incision of Henry gives access to the back of the tibia. The fracture is cleared of debris, and the large posterior fragment is carefully replaced with firm pressure. Reduction is maintained by a temporary transfixion pin, and at this stage it is advisable to check the position radiographically. Screws are then inserted to engage the anterior tibial cortex, and the pin is withdrawn. After closure of the wounds a crêpe bandage is applied firmly over a number of turns of plaster wool and the tourniquet is then removed. Care after operation-The foot of the bed is elevated during the period of wound healing. The first dressing, which has to be bulky to achieve haemostasis, is changed in the operation theatre two days after operation and a small crepe bandage is applied without padding. The patient is then encouraged to do ankle and foot exercises for five minutes during each period of half an hour throughout the day. These exercises are not painful because the fractures are held firmly by the screws (so long as the patient is in bed) and the range of movement gradually increases. When full movement has been restored (in this series the range was from seven to forty days) the stitches are removed and a plaster extending from the base of the toes to just below the knee is applied. After two days, when the plaster is dry, the patient is allowed out of bed and is taught to walk correctly using two sticks. On leaving hospital the patient is advised to walk as much as possible and to continue his normal activities as far as possible. Housewives resume most of their normal duties and patients with light semisedentary occupations return to work. The average period of plaster immobilisation was five weeks (range three to eight weeks). In fifteen patients, mostly with Pl and PLI fractures of the medial malleolus alone, fixation was sufficiently firm to permit unsupported weight bearing on the injured limb during the fourth week. After removal of the plaster joint movements are quickly regained without pain since the dense adhesions, which are constantly present at this stage when an injured ankle has been immobilised from the time of the reduction, are avoided by the active movements during the crucial healing phase (of about three weeks) and do not re-form. Further exercises under supervision, after removal of the plaster, are frequently unnecessary and the patient quickly returns to his normal work and activities.

Removal of the screws or pins is rarely necessary because their presence is rarely associated with any pain or discomfort. In this series the screws or pins were removed in ten instances for the following reasons: temporary pins, four cases; incorrectly placed screws, three cases; aching, two cases; sepsis, one case.

Post-traumatic arthritis-In the diagnosis of arthritis we have paid attention to any diminution of joint space, any irregularity of the articular surface and also to evidence of ossification at the joint margins. These ossifications, at the site of ligamentous attachment, indicate injury to ligaments and are not caused by a progressive form of arthritis. On these strict criteria radiographic changes were found in 37 per cent of our total material, but it was noted, as shown by Klossner, that marginal ossifications did not progress with increasing length of the follow-up. Opinions differ about the significance of arthritic changes that may develop after 
ankle injuries. Thus Magnusson (1944) in a series of ankle fractures treated conservatively found arthritis in 49 per cent, and Vasli (1957) in a series of fractures treated by operation found arthritis in 43 per cent. However, neither of these writers was able to demonstrate any definite relationship between the presence of arthritis and the occurrence of symptoms. In the present series twenty-two of the 104 ankles in which reduction was "anatomical "were the site of some aching or discomfort, although of these only nine had radiographic arthritis. Of the twenty-two ankles in which reduction was "fair," seven were the site of pain or discomfort and all of these had arthritis. All eight ankles in which reduction was "poor" had arthritis and six were painful. It seems that symptoms become more marked as the degree of malunion and of arthritis increases.

Klossner found that more severe arthritic changes were associated with disability and this has proved to be so in the present series. Thus arthritic change was found in twenty-nine ( 27 per cent) of those patients whose results were objectively graded as "good," in fifteen ( 79 per cent) of those with results graded as "fair" and in five (100 per cent) of those with results graded as " poor."

Walheim (1937) considered that young people had no particular tendency to arthritis after severe fractures and both Magnusson (1944) and Klossner (1962) referred to the higher

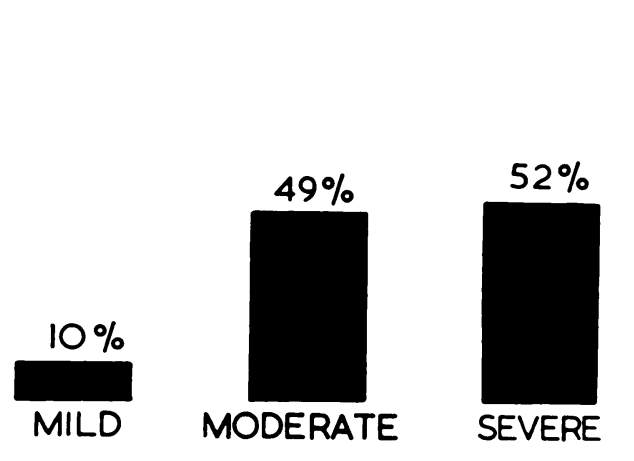

\section{INITIAL DISPLACEMENT}

FIG. 41

Percentage incidence of arthritis in relation to initial degree of displacement.

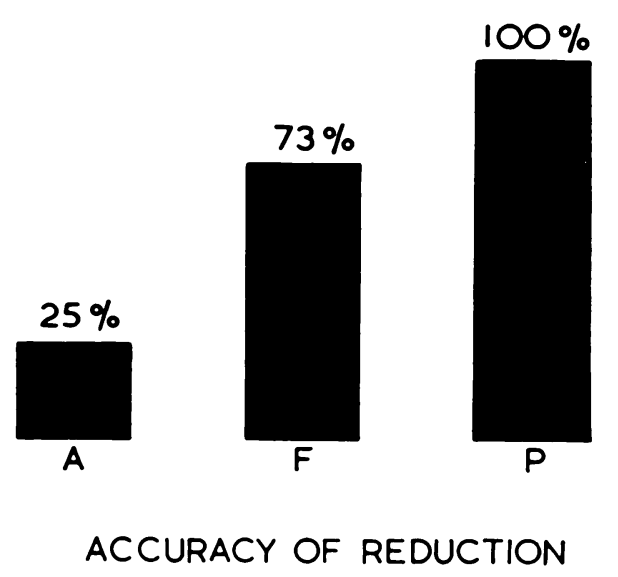

FIG. 42

Percentage incidence of arthritis in relation to accuracy of reduction $\mathrm{A}=$ Anatomical; $\mathrm{F}=$ Fair; $\mathbf{P}=$ Poor.

incidence of arthritis as age increased. The latter finding is borne out in the present series but this is because of the increased incidence in older people of SL fractures which are more liable to develop arthritis (43 per cent).

Effect of initial degree of displacement-There is a definite relationship between the incidence of arthritis and the initial degree of displacement of the fractures ranging from 10 per cent in the slightly displaced group to 52 per cent in the more severely displaced fractures (Fig. 41). It seems clear that severe damage to the articular surfaces such as has been found at the medial corner of the tibia in supination fractures (Klossner 1962) and in compression fractures at other sites (Palmer 1950) would be expected to predispose to arthritis. Jergesen (1959) also referred to injury to the articular cartilage and Cox and Laxson (1952) indicated that damage to the subchondral bone might be expected to interfere with the nutrition of the articular cartilage. In the present series the highest incidence of arthritis was found in the displaced SL fractures. In these it is common for damage to the articular surface in the region of the syndesmosis to be seen on the initial radiograph.

Effect of accuracy of reduction-The most important factor determining the onset of arthritis after fractures of the ankle is, however, the accuracy of the reduction. Lewis and Graham (1940) 
who described arthritis in eighteen patients after ankle fractures reported that only three of the patients had " nearly perfect reduction." Jergesen (1959) emphasised the importance of accurate reduction in preventing arthritis, and Klossner (1962) thought the same but he stated also that arthritis was not always prevented by this means although it was then usually mild.

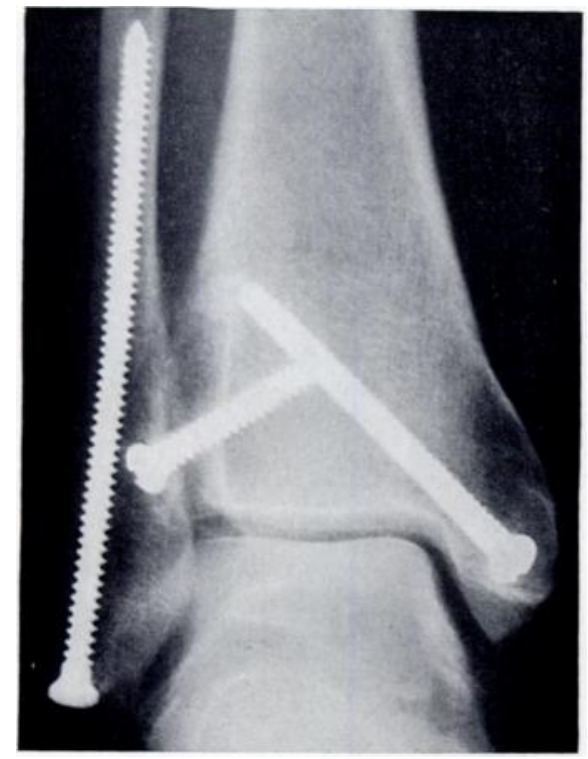

FIG. 43

The ankle shown in Figures 2 to 5 , six years after operation. Note that there is virtually no degenerative change. Cedell and Wiberg (1962) stated that the greater the load on a joint the more likely it was that irregularity of the joint would give rise to symptoms from arthritis. These views are supported by the findings in this series (Fig. 42). Arthritis was found in 25 per cent of the patients with reduction graded as " anatomical," in 73 per cent of those with reduction graded as "fair" and in 100 per cent of those in whom reduction had been poor.

When reduction is really accurate and fixation is firm, the onset of arthritis can be prevented or at least deferred for many years (Fig. 43).

\section{SUMMARY}

1. This paper presents a series of 135 patients with displaced ankle fractures treated by rigid internal fixation followed by early joint exercises in bed until movements were restored and followed then by full weight bearing in a plaster.

2. The advantages obtained are as follows: A high standard of reduction can be achieved and maintained. The joint movements are established before organisation of the traumatic exudate. Weight bearing in a plaster reduces the degree of disability and prevents osteoporosis. Further remedial treatment after removal of the plaster is usually unnecessary.

3. All but five of the fractures ( 3.7 per cent) could be classified in the manner described by Lauge-Hansen.

4. This classification is the most satisfactory of those available and is recommended for general use.

5. Anatomical reduction was obtained in 102 patients ( 77 per cent), with good objective clinical results in 108 patients ( 82 per cent).

6. The quality of the clinical result depends mostly on the accuracy of the reduction, to a lesser extent on the degree of initial displacement, and least on the type of fracture.

7. It is considered that the traditional concept of diastasis requires modification; it is felt that the term lateral ankle instability, which includes low fracture of the fibula (intraosseous diastasis) is preferable.

8. Internal fixation of the syndesmosis is to be avoided except in rare instances.

9. The incidence of arthritis is shown to depend mostly upon the accuracy of reduction; the initial degree of displacement is also of importance.

We wish to thank Mr J. D. Crossley for the prints of the radiographs, and Mrs Joan Burwell for secretarial assistance.

\section{REFERENCES}

Ashurst, A. P. C., and Bromer, R. S. (1922): Classification and Mechanism of Fractures of the Leg Bones Involving the Ankle. Archives of Surgery, 4, 51.

Banks, S. W. (1949): The Treatment of Non-union of Fractures of the Medial Malleolus. Journal of Bone and Joint Surgery, 31-A, 658. 
Bergkvist, A., Hultengren, N., Lindholm, A., and Lindvall, N. (1958): Circumferential Wire Fixation of the Lateral Malleolus for Fractures at the Ankle. Acta Chirurgica Scandinavica, 115, 476.

Biström, O. (1952): Conservative Treatment of Severe Ankle Fractures. Acta Chirurgica Scandinavica, Supplementum 168.

Bonnin, J. (1950): Injuries to the Ankle. London: Heinemann Medical Books Ltd.

Braunstein, P. W., and Wade, P. A. (1959): Treatment of Unstable Fractures of the Ankle. Annals of Surgery, 149, 217.

Burgess, E. (1944): Fractures of the Ankle. Journal of Bone and Joint Surgery, 26, 721.

Cedell, C. A., and Wiberg, G. (1962): Treatment of Eversion-Supination Fracture of the Ankle (2nd Degree). Acta Chirurgica Scandinavica, 124, 41.

Charnley, J. (1957): The Closed Treatment of Common Fractures. Second edition. Edinburgh and London: E. \& S. Livingstone Ltd.

Close, J. R. (1956): Some Applications of the Functional Anatomy of the Ankle Joint. Journal of Bone and Joint Surgery, 38-A, 761.

Coonrad, R. W., and Bugg, E. I., Jun. (1954): Trapping of the Posterior Tibial Tendon and Interposition of Soft Tissue in Severe Fractures About the Ankle Joint. Journal of Bone and Joint Surgery, 36-A, 744.

Cox, F. J., and Laxson, W. W. (1952): Fractures About the Ankle Joint. American Journal of Surgery, 83, 674.

Darrach, W. (1942): Fractures Around the Ankle Joint. New England Journal of Medicine, 226, 333.

Grath, G. B. (1960): Widening of the Ankle Mortise. Acta Chirurgica Scandinavica, Supplementum 263.

Henry, A. K. (1945): Extensile Exposure Applied to Limb Surgery. Edinburgh: E. \& S. Livingstone Ltd. Iselin, M., and de Vellis, H. (1961): La primauté du péroné dans les fractures du cou-de-pied. Mémoires de l'Académie de Chirurgie, 87, 399.

Jergesen, F. (1959): Open Reduction of Fractures and Dislocations of the Ankle. American Journal of Surgery, 98, 136.

Jones, W. C., and Neal, E. G. (1962): Survey of Fractures of the Medial Malleolus. Southern Medical Journal, $55,1054$.

Kleiger, B. (1954): The Diagnosis and Treatment of Traumatic Lateral Ankle Instability. New York State Journal of Medicine, 54, 2573.

KLOSSNER, O. (1962): Late Results of Operative and Non-operative Treatment of Severe Ankle Fractures. Acta Chirurgica Scandinavica, Supplementum 293.

Kristensen, T. B. (1956): Fractures of the Ankle. VI. Follow-up Studies. Archives of Surgery, 73, 112.

LAmARE, J. P., and Scheer, M. (1960): Indications du traitement chirurgical des fractures bimalléolaires par adduction. Gazette Médicale de France, 67, 1143.

LAMBOTtE, A. (1907): L'intervention opératoire dans les fractures récentes et anciennes. Bruxelles: J. Lamertain.

LANE, W. A. (1914): The Operative Treatment of Fractures. Second edition. London: The Medical Publishing Company Limited.

Lauge-Hansen, N. (1948): Fractures of the Ankle. Archives of Surgery, 56, 259.

Lauge-Hansen, N. (1950): Fractures of the Ankle. Archives of Surgery, 60, 957.

LAUGe-HANSEN, N. (1952): Fractures of the Ankle. Archives of Surgery, 64, 488.

Lauge-Hansen, N. (1954): Fractures of the Ankle. American Journal of Roentgenology, 71, 456.

Lewis, R. W., and Graham, W. C. (1940): Secondary Osteoarthritis Following Fractures of the Ankle. American Journal of Surgery, 49, 210.

MacKinnon, A. P. (1928): Fracture of the Lower Articular Surface of the Tibia in Fracture Dislocation of the Ankle. Journal of Bone and Joint Surgery, 10, 352.

McLAughlin, H. L., and Ryder, C. T., Jun. (1949): Open Reduction and Internal Fixation for Fractures of the Tibia and Ankle. Surgical Clinics of North America, 29, 1523.

Magnusson, R. (1944): On the Late Results in Non-operated Cases of Malleolar Fractures. Acta Chirurgica Scandinavica, Supplementum 84.

de MARnefre, R. (1955): Indications du traitement orthopédique ou chirurgical dans les fractures malléolaires fermées. Acta Chirurgica Belgica, 54, 411.

MAYer, H. (1956): Die operative Behandlung der Luxationsfrakturen des oberen Sprunggelenkes bei gleichzeitiger Sprengung des Ligamentum interosseum zwischen Tibia und Fibula. Chirurg, 27, 509.

Meekison, D. M. (1945): Some Remarks on Three Common Fractures. Fractures of the Medial Malleolus. Journal of Bone and Joint Surgery, 27, 80.

Mrtchell, C. L., and Fleming, J. L. (1959): Fractures and Fracture-Dislocations of the Ankle. Postgraduate Medicine, 26, 773.

Muller, G. M. (1945): Fractures of the Internal Malleolus. British Medical Journal, ii, 320.

MurRay, C. R. (1944): The Detailed Operative Technique for Open Reduction and Internal Fixation of Fractures of the Long Bones. Journal of Bone and Joint Surgery, 26, 307.

Nelson, M. C., and Jensen, N. K. (1940): The Treatment of Trimalleolar Fractures of the Ankle. Surgery, Gynecology and Obstetrics, 71, 509.

VOL. 47 B, NO. 4, NOVEMBER 1965

D 
Palmer, I. (1950): Malleolarfrakturer och deras behandling. Nordisk Medicin, 44, 1593.

Perkins, G. (1958): Fractures and Dislocations. London: University of London, The Athlone Press.

QuIGLeY, T. B. (1959): Fractures and Ligament Injuries of the Ankle. American Journal of Surgery, 98, 477.

Rose, G. K. (1962): Ankle Injuries. In Modern Trends in Orthopaedics. 3. Fracture Treatment. Edited by J. M. P. Clark. London: Butterworth \& Co. (Publishers) Ltd.

Scort, J. C. (1962): Fractures of the Tibia and Fibula. In Modern Trends in Orthopaedics. 3. Fracture Treatment. Edited by J. M. P. Clark. London: Butterworth \& Co. (Publishers) Ltd.

Smrrh, H. (1956): Fractures. In Campbell's Operative Orthopaedics: Third edition. London: Henry Kimpton. SPEed, J. S., and Boyd, H. B. (1936): Operative Reconstruction of Malunited Fractures About the Ankle Joint. Journal of Bone and Joint Surgery, 18, 270.

Trethowan, W. H. (1926): The Operative Treatment of Ankle Fractures. Lancet, i, 90.

VASLI, S. (1957): Operative Treatment of Ankle Fractures. Acta Chirurgica Scandinavica, Supplementum 226.

WalHeim, T. (1937): Intraarticular Malleolar Fractures. Acta Chirurgica Scandinavica, 79, 166.

WATSON-Jones, R. (1955): Fractures and Joint Injuries. Fourth Edition, Vol. II. Edinburgh and London: E. \& S. Livingstone Ltd.

Zuelzer, W. A. (1951): Fixation of Small but Important Bone Fragments with a Hook Plate. Journal of Bone and Joint Surgery, 33-A, 430. 